\title{
Avaliação do comportamento de revestimentos em argamassas estabilizadas submetidas a tratamento superficial com aditivos cristalizantes
}

Behaviour assessment of ready-to-use mortar with
waterproofing treatment with crystallizing admixtures

\author{
Ana Cláudia Akele Jantsch \\ Gihad Mohamad \\ Raquel Petry Brondani Schmidt \\ Juliana Pippi Antoniazzi \\ André Lübeck (iD
}

${ }^{1}$ Ana Cláudia Akele Jantsch ${ }^{1}$ Universidade Federal de Santa Maria Santa Maria - RS - Brasil

${ }^{2}$ Gihad Mohamad

2Universidade Federal de Santa Maria Santa Maria - RS - Brasil

${ }^{3}$ Raquel Petry Brondani Schmidt ${ }^{3}$ Universidade Federal de Santa Maria Santa Maria - RS - Brasil

${ }^{4} J u l i a n a$ Pippi Antoniazzi ${ }^{4}$ Universidade Federal de Santa Maria Santa Maria - RS - Brasil

${ }^{5}$ André Lübeck

${ }^{5}$ Universidade Federal de Santa Maria Santa Maria - RS - Brasil

Recebido em 25/09/19 Aceito em 20/08/20

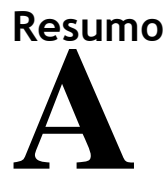

presença da água é uma das principais causas do surgimento e da disseminação de manifestações patológicas em revestimentos argamassados. Tal problema põe em risco a capacidade de proteção dos revestimentos e, consequentemente, sua durabilidade,

permitindo a degradação precoce desses materiais. A utilização de aditivos impermeabilizantes, como os cristalizantes, visa à criação de uma barreira à penetração da água. Assim, a presente pesquisa avaliou argamassas estabilizadas de $36 \mathrm{~h}$ e de $72 \mathrm{~h}$, com e sem a adição de tratamentos cristalizantes (líquido e em pó), para verificar seu comportamento quanto à ação de umidade no estado líquido e de vapor d'água. Para isso, foram avaliadas a resistência mecânica e a permeabilidade desses materiais. Pode-se concluir que as argamassas de $36 \mathrm{~h}$ apresentaram melhores resultados quando comparadas às argamassas de $72 \mathrm{~h}$. A aplicação de tratamentos cristalizantes contribuiu para a redução da absorção de água e para o aumento da resistência mecânica. $\mathrm{O}$ cristalizante líquido demonstrou ser mais apropriado, enquanto o cristalizante em pó diminuiu a permeabilidade ao vapor d'água, o que causa prejuízos ao revestimento.

Palavras-chave: Argamassa estabilizada. Aditivo cristalizante. Permeabilidade à água. Permeabilidade ao vapor.

\section{Abstract}

The presence of water in coating rendering mortar is the main cause of the onset and dissemination of pathological problems, compromising durability and the surface protection of walls under harsh weather. On the other hand, waterproofing treatments as crystallising admixtures are designed to create a barrier against water penetration. This research study assessed 36 hours' and 72 hours' ready-to-use mortars, with and without the application of crystallising admixtures (liquid and powder), in order to evaluate their behaviour in the presence of humidity in the liquid and vapour states. The mechanical strength and permeability were evaluated in hardened mortars. The conclusion was that the $36 \mathrm{~h}$ mortars had the best results. The treatment with crystallising admixtures reduced water absorption and increased mechanical strength. The liquid crystallising admixture proved to be more appropriate, since the powder crystallising admixture decreased vapour permeability, which causes damage to the coating.

Keywords: Ready-to-use mortar. Crystallizing admixtures. Water and vapour permeability.

JANTSCH, A. C. A.; MOHAMAD, G.; SCHMIDT, R. P. B.; ANTONIAZZI, J. P.; LÜBECK, A. Avaliação do comportamento 


\section{Introdução}

Nos dias atuais, com frequência se discute no meio técnico a importância da durabilidade e da vida útil das edificações visando, além da segurança, à busca pela sustentabilidade e racionalização dos processos construtivos. Esses aspectos são indispensáveis para a execução de obras com qualidades compatíveis às necessidades e exigências do mundo contemporâneo. Nesse sentido e mais especificamente quando se trata de fachadas de edificações, é primordial o uso de sistemas de revestimento eficientes em termos de envoltória protetiva, que proporcionem às construções condições adequadas de salubridade, durabilidade, estanqueidade, capacidade funcional e conforto ao usuário ao longo da vida útil da edificação.

Da mesma forma, a busca por racionalizar e acelerar o processo construtivo faz com que sejam buscadas alternativas que aumentem o grau de industrialização empregado nos canteiros de obra, e nesse sentido as argamassas estabilizadas têm sido uma opção bastante empregada em revestimentos de fachadas, sendo fornecidas prontas para o uso e com durabilidade no estado fresco de até $72 \mathrm{~h}$. Por serem produzidas em grande escala em usinas especializadas, a tendência é que haja maior controle tecnológico e fiscalização por parte dos fabricantes, tanto dos materiais como do processo produtivo (CASALI et al., 2011; BAUER et al., 2015). Para promover maior trabalhabilidade e diminuir a exsudação (ROMANO; CINCOTTO; PILEGGI, 2018), a argamassa estabilizada recebe em sua composição aditivo incorporador de ar, o que também proporciona maior retenção de água (MATOS, 2013; ALVES, DO Ó, 2005; BRUGALI; CASAGRANDE; STOLZ, 2019).

Ao mesmo tempo, essa incorporação de ar tende a deixar a argamassa mais porosa, tornando-a mais permeável e suscetível à ação deletéria devido à umidade e aos agentes agressivos (ROMANO et al., 2011). Além do aditivo incorporador de ar, as argamassas estabilizadas também empregam aditivo estabilizador de hidratação, o qual agem de forma a retardar o tempo de início de pega, a fim de garantir a ampliação do tempo de aplicação e a estabilidade durante a execução do revestimento (PAOLINI; KHURANA, 1998; CHEUNG et al., 2011; WATTS; FERRARO, 2017). Em contrapartida, com o emprego dos estabilizadores, a argamassa pode apresentar aumento na retração plástica e na exsudação de água, conforme observado por Neville e Brooks (2013), devido à maior quantidade de água livre no sistema.

A combinação dos aditivos incorporador de ar e estabilizador de hidratação, bem como seus efeitos sobre a argamassa fresca e endurecida, vem sendo tema frequente de estudos. A aplicação e a dosagem desses aditivos, cada vez mais, requerem uma análise conjunta (ANTONIAZZI, 2019), considerando as bases químicas empregadas (CHEUNG et al., 2011; GUINDANI, 2018), o tipo de cimento (CASALI et al., 2018), a granulometria do agregado (BAUER; OLIVEIRA, 2017) e as características da mistura (ROMANO et al., 2009; FUKUI et al., 2018), entre outros fatores. Dessa forma, os estudos deveriam associar teores mais baixos de aditivos com fatores que potencializassem seus efeitos, buscando explorar sua máxima eficiência sem comprometer as propriedades da argamassa. No entanto, as argamassas estabilizadas são comercializadas justamente por seu tempo de estabilização, sabendo-se que ocorrerá perda do índice de consistência com o passar das horas devido à diminuição do teor de ar incorporado e ao início das reações de hidratação do cimento (KEBHARD; KAZMIERCZAK, 2017; BAUER; OLIVEIRA, 2017; ANTONIAZZI, 2019). Assim, buscando ampliar esse tempo de estabilização, são utilizados teores mais elevados de aditivos (CAMPOS; MACIOSKI; CASALI, 2013; OLIVEIRA, 2017), que acabam refletindo em perda de resistência mecânica (LOOTENS; BENTZ, 2016; BAUER; OLIVEIRA, 2017; BELLEI; CATEN, 2019; SCHACKOW et al., 2019).

Dessa forma, as vantagens executivas proporcionadas pela argamassa estabilizada podem ser minoradas pelas desvantagens do comportamento físico do material quando aplicado, principalmente relacionadas à permeabilidade. Apesar de essas argamassas se destacarem como soluções economicamente viáveis para revestimentos, por se tratar de um produto relativamente novo, o desempenho em serviço ainda é, por vezes, desconhecido. O desempenho pós-aplicação tende a refletir problemas gerados ainda do estado fresco da argamassa, sendo recorrente o aparecimento de manifestações patológicas nos primeiros anos de uso. Entre estas se salientam as manifestações provocadas por penetração de umidade nas fachadas, produzindo, por consequência, mapeamentos, manchas e bolores. A permeabilidade ao vapor é uma característica desejável nas argamassas, considerando-se que o aprisionamento dele é um fator nocivo ao material. Já a permeabilidade à água e a outros líquidos representa um risco por si só e permite a infiltração de agentes agressivos, sendo, portanto, uma característica não desejável (NEVILLE, 2015).

Em algumas obras, tem sido empregados como solução técnica sistemas de impermeabilização com capacidade de penetrar e bloquear os poros, reagindo quimicamente com a pasta. Entre esses sistemas destaca-se a aplicação de aditivos impermeabilizantes de efeito cristalizante como uma possível solução para 
impedir a penetração de água no estado líquido, mantendo apenas a passagem de ar e de vapor d'água. Esses aditivos cristalizantes são produtos definidos por seus fabricantes como capazes de penetrar na rede capilar do material, chegando até seus poros e reagindo quimicamente com os elementos que constituem a pasta para criar um sistema capaz de obstruir a passagem de água.

Estudos têm mostrado que o uso de aditivos cristalizantes em argamassas, mesmo em teores elevados, não altera o comportamento em idades iniciais. No entanto, em idades superiores, o emprego do aditivo pode diminuir a absorção de água em até $80 \%$ em relação a uma argamassa sem o aditivo, a depender do teor empregado (REITERMAN; BÄUMELT, 2014). As propriedades mecânicas das argamassas não são influenciadas de forma significativa pela adição desses aditivos (HODUL et al., 2019). Além das argamassas de revestimento, esses bloqueadores de umidade, como também são chamados, demonstraram ser eficazes na redução dos níveis de umidade superficial em tijolos, na interface tijolo-argamassa e em argamassas de assentamento (AL-KHEETAN; RAHMAN; CHAMBERLAIN, 2018a). Al-Kheetan, Rahman e Chamberlain (2018b) constataram redução significativa da absorção de água utilizando-se altos teores de aditivo (8\%) quando aplicado em concretos, como substituição do cimento, porém associada a uma pequena redução da resistência. Para um teor de $2 \%$ não houve redução de resistência, mas houve redução na absorção de água. Segundo Granneman, Lubelli e Van Hees (2019), um dos usos mais promissores para os aditivos cristalizantes está na incorporação a seco ao nível industrial na produção de argamassas para as mais variadas aplicações, contudo relatam que ainda não existem estudos que avaliem o comportamento dessas argamassas em termos de durabilidade e de manutenção do desempenho.

Nenhum dos estudos encontrados sobre o emprego de aditivos cristalizantes avaliou a ação deles sobre argamassas estabilizadas ou com alto teor de ar incorporado. São muitas as lacunas existentes ainda sobre esse tipo de revestimento e seu desempenho. Além disso, não existe normalização brasileira para a especificação das propriedades requeridas em argamassas estabilizadas nos estados fresco e endurecido. Por isso se evidencia no meio técnico a necessidade de estudos do comportamento acerca da permeabilidade desse material no estado endurecido, a fim de garantir as propriedades de estanqueidade dos revestimentos executados e diminuir as patologias devidas à umidade.

Nesse contexto, o objetivo desta pesquisa foi analisar o comportamento de argamassas estabilizadas de $36 \mathrm{~h}$ e de $72 \mathrm{~h}$ do tipo monocamada externa e interna com a aplicação de aditivos cristalizantes na superfície da amostra. Com isso, pretendeu-se determinar as características físicas e mecânicas das argamassas estabilizadas no estado endurecido, avaliando os efeitos do aditivo cristalizante sobre a superfície da argamassa e seu impacto na permeabilidade.

\section{Método de pesquisa}

\section{Caracterização dos materiais}

As argamassas estabilizadas de $36 \mathrm{~h}$ e de $72 \mathrm{~h}$ para uso em revestimento foram coletadas já prontas na própria empresa fabricante, localizada na região central do Rio Grande do Sul. Conforme informações obtidas no local, os materiais empregados na composição das argamassas foram cimento Portland composto com material pozolânico (CPII-Z-32-RS), agregado miúdo (areia média), água potável, aditivo retardador de pega (estabilizante) e aditivo incorporador de ar. O proporcionamento dos materiais em termos percentuais (definido em massa) é apresentado na Figura 1, e na Tabela 1 são apresentados os consumos dos insumos por metro cúbico de argamassa produzido. Da análise da figura percebe-se que a argamassa de $72 \mathrm{~h}$ possui maior quantidade dos aditivos incorporador de ar e estabilizante se comparada à argamassa de $36 \mathrm{~h}$.

A areia empregada no traço foi uma areia média proveniente de jazida própria, com armazenamento ao ar livre no pátio da empresa fornecedora das argamassas estabilizadas. De acordo com a empresa, a areia não é lavada antes de ser utilizada para a confecção do traço. Os dados de caracterização obtidos na empresa são apresentados na Tabela 2, e a curva granulométrica é apresentada na Figura 2. Nessa figura são indicadas as zonas ótima e utilizável segundo a norma NBR 7211 (ABNT, 2019).

O cimento é do tipo CPII-Z-32-RS (ABNT, 2018), fornecido por empresa nacional. A Tabela 3 apresenta a composição química e física do cimento.

$\mathrm{Na}$ composição das argamassas estabilizadas foram utilizados dois tipos de aditivos, o primeiro era um retardador de pega (estabilizante), Centripor Retard 225, do fabricante MC-Bauchemie, para que a argamassa possa ser utilizada durante um maior período, e o segundo, um incorporador de ar, Centripor 411, do mesmo fabricante, para proporcionar maior trabalhabilidade. As características dos aditivos são apresentadas na Tabela 4 . 
Figura 1 - Proporcionamento dos materiais nas argamassas estabilizadas

Traço para argamassas de revestimento de $36 \mathrm{~h}$

Traço para argamassas de revestimento de $72 \mathrm{~h}$
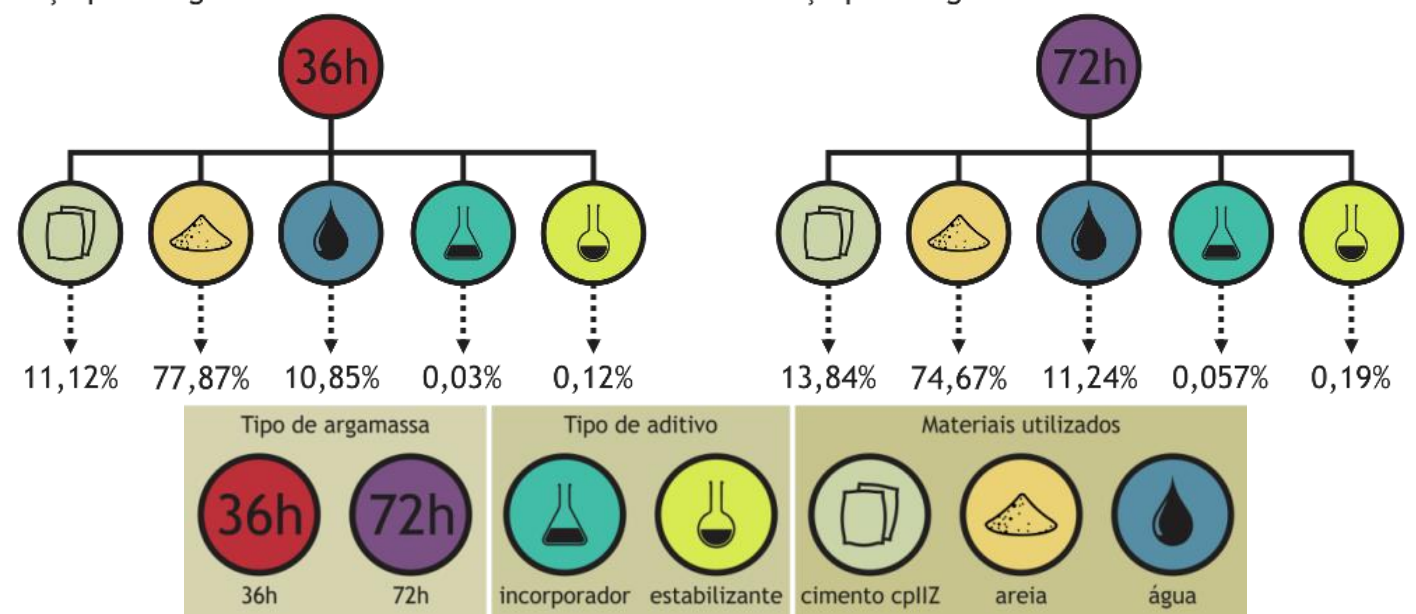

Materiais utilizados

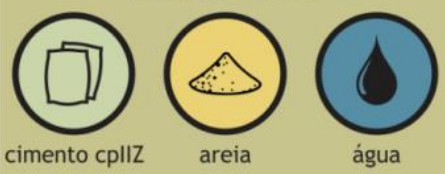

Fonte: adaptada do fabricante das argamassas estabilizadas.

Tabela 1 - Consumo de materiais por metro cúbico de argamassa produzido $\left(\mathrm{kg} / \mathrm{m}^{3}\right)$

\begin{tabular}{c|c|c|c|c|c}
\hline Argamassa & Cimento & Areia & Água & Incorporador & Estabilizador \\
\hline $36 \mathrm{~h}$ & 210 & 1.470 & 205 & 0,6 & 2,31 \\
$72 \mathrm{~h}$ & 240 & 1.295 & 195 & 1 & 3,3 \\
\hline
\end{tabular}

Tabela 2 - Caracterização do agregado miúdo

\begin{tabular}{|c|c|c|c|c|c|c|c|c|c|}
\hline \multicolumn{7}{|c|}{ Porcentagem retida acumulada $(\%)$} & \multirow{3}{*}{$\begin{array}{c}\text { Diâmetro máximo } \\
\text { característico }(\mathbf{m m})\end{array}$} & \multirow{3}{*}{$\begin{array}{c}\text { Módulo } \\
\text { de } \\
\text { finura }\end{array}$} & \multirow{3}{*}{$\begin{array}{c}\text { Massa } \\
\text { específica } \\
\left(\mathbf{g} / \mathrm{cm}^{3}\right)\end{array}$} \\
\hline \multicolumn{7}{|c|}{ Abertura da malha (mm) } & & & \\
\hline 4,8 & 2,4 & 1,2 & 0,6 & 0,3 & 0,15 & Fundo & & & \\
\hline 0 & 2 & 7 & 32 & 75 & 93 & 100 & 2,40 & 2,09 & 2,63 \\
\hline
\end{tabular}

Fonte: fabricante das argamassas estabilizadas.

Figura 2 - Distribuição granulométrica da areia utilizada

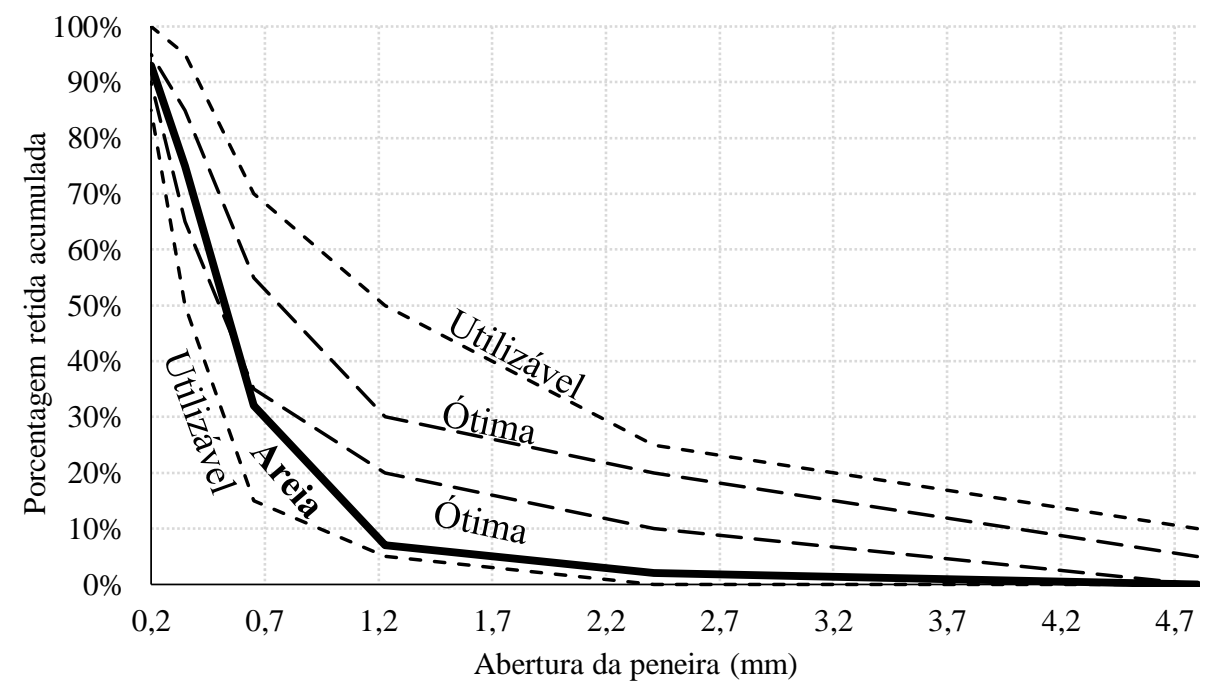

84 Jantsch, A. C. A.; Mohamad, G.; Schmidt, R. P. B.; Antoniazzi, J. P.; Lübeck, A. 
Tabela 3 - Caracterização do cimento CPII-Z-32-RS

\begin{tabular}{|c|c|c|c|c|c|c|c|}
\hline Tipo & \multicolumn{2}{|l|}{ Ensaio } & $\begin{array}{c}\text { Limite de } \\
\text { norma }\end{array}$ & Média & $\begin{array}{l}\text { Desvio } \\
\text { padrão }\end{array}$ & Mínimo & Máximo \\
\hline \multirow{4}{*}{ 芑 } & \multirow{4}{*}{\multicolumn{2}{|c|}{$\begin{array}{c}\text { Perda ao fogo }(\%) \\
\mathrm{MgO}(\%) \\
\mathrm{SO}_{3}(\%) \\
\text { Resíduo insolúvel }(\%)\end{array}$}} & $\leq 6,5$ & 3,3 & 0,3 & 2,8 & 4,2 \\
\hline & & & $\leq 6,5$ & 6,2 & 0,2 & 5,9 & 6,5 \\
\hline & & & $\leq 4$ & 2,1 & 0,1 & 2,0 & 2,4 \\
\hline & & & $\leq 16$ & 12,6 & 0,7 & 11,2 & 13,9 \\
\hline \multirow{11}{*}{ 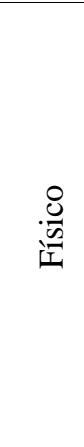 } & \multicolumn{2}{|c|}{ Massa específica $\left(\mathrm{g} / \mathrm{cm}^{3}\right)$} & \multicolumn{5}{|c|}{2,96} \\
\hline & \multicolumn{2}{|c|}{$\begin{array}{l}\text { Finura \#200 }(\%) \\
\text { Finura \#325 }(\%)\end{array}$} & $\leq 12$ & 0,3 & 0,1 & 0,2 & 0,6 \\
\hline & \multicolumn{2}{|c|}{ Finura \#325 (\%) } & $\mathrm{N} / \mathrm{A}$ & 2,8 & 0,2 & 2,5 & 3,2 \\
\hline & \multicolumn{2}{|c|}{ Blaine $\left(\mathrm{cm}^{2} / \mathrm{g}\right)$} & $\geq 2600$ & 4704 & 244 & 3850 & 4970 \\
\hline & \multicolumn{2}{|c|}{ Água de consistência (\%) } & $\mathrm{N} / \mathrm{A}$ & 30,2 & 0,3 & 29,8 & 30,8 \\
\hline & \multicolumn{2}{|c|}{ Início tempo de pega (min) } & $\geq 60$ & 229 & 24 & 195 & 270 \\
\hline & \multicolumn{2}{|c|}{ Fim tempo de pega (min) } & $\leq 600$ & 298 & 27 & 255 & 360 \\
\hline & \multicolumn{2}{|c|}{ Expansibilidade a quente $(\mathrm{mm})$} & $\leq 5$ & 0 & 0 & 0 & 1 \\
\hline & \multirow{3}{*}{$\begin{array}{c}\text { Resistência à } \\
\text { compressão (MPa) }\end{array}$} & 3 dias & $\geq 10$ & 26,1 & 1,8 & 20,1 & 27,7 \\
\hline & & 7 dias & $\geq 20$ & 31,7 & 1,5 & 29,3 & 34,4 \\
\hline & & 28 dias & $\geq 32 ; \leq 49$ & 39,3 & 0,1 & 39,3 & 39,4 \\
\hline
\end{tabular}

Fonte: fabricante do cimento Portland.

Tabela 4 - Caracterização dos aditivos

\begin{tabular}{c|c|c}
\hline Características & Incorporador de ar & $\begin{array}{c}\text { Retardador de pega } \\
\text { (estabilizante) }\end{array}$ \\
\hline Solubilidade com água & solúvel em água & solúvel em água \\
Densidade a $23^{\circ} \mathrm{C}\left(\mathrm{g} / \mathrm{cm}^{3}\right)$ & 1,00 & 1,17 \\
pH a $23{ }^{\circ} \mathrm{C}$ & $7,0-9,0$ & $5,0-7,0$ \\
Estado físico & líquido & líquido \\
Coloração & amarelo & marrom claro \\
Dosagem recomendada & $0,1-0,5 \%$ da massa de cimento & $0,2-1,5 \%$ da massa de cimento \\
\hline
\end{tabular}

Fonte: adaptada do fabricante dos aditivos.

Após a coleta no fabricante, as argamassas foram transportadas em sacos plásticos até o Laboratório de Materiais de Construção Civil da Universidade Federal de Santa Maria. A argamassa de 36 h foi utilizada logo após sua chegada, sendo disposta em baldes para homogeneização. Já a argamassa de $72 \mathrm{~h}$ de estabilização, conforme recomendação do fornecedor, permaneceu em repouso por 3 dias com película de água de $2 \mathrm{~cm}$, acondicionada em baldes. Na sequência, a película de água foi retirada e se promoveu a homogeneização do material previamente à realização dos ensaios.

\section{Aplicação dos tratamentos cristalizantes}

A aplicação dos tratamentos cristalizantes foi realizada sobre as amostras de argamassa estabilizada de $36 \mathrm{~h}$ e de $72 \mathrm{~h}$ ao serem atingidos os 28 dias de idade. Conforme recomendado pelo fabricante, após a aplicação foi necessário aguardar, no mínimo, 14 dias para promover a cura úmida do material por metade desse tempo, para, então, ensaiar as amostras. Foram utilizados dois tipos de cristalizantes, um líquido e um em pó, aqui denominados "R" e "P". As características dos cristalizantes são apresentadas na Tabela 5.

$\mathrm{O}$ cristalizante $\mathrm{R}$ é um material pronto, comercializado no estado líquido, destinado à aplicação interna e externa na parede, específico para uso em argamassas. Já o cristalizante P é um material semipronto, comercializado em forma de pó e descrito pelo fabricante como um "material de impermeabilização por cristalização integral, aplicado superficialmente, que impermeabiliza e protege o concreto em profundidade".

Com o intuito de facilitar a leitura das imagens apresentadas na sequência, foi utilizada a simbologia gráfica da Figura 3.

Quanto ao cristalizante R, o fornecedor indica consumo de $250 \mathrm{ml} / \mathrm{m}^{2}$ para aplicação apenas na superfície do material. A quantidade de cristalizante $\mathrm{R}$ utilizada foi calculada de acordo com a área superficial da amostra que receberia o tratamento. 
Já para o cristalizante $\mathrm{P}$, de acordo com o fabricante, o rendimento é variável, dependendo da área de aplicação, entretanto todas as recomendações são feitas para uso em concreto. Indica-se um rendimento de $800 \mathrm{~g} / \mathrm{m}^{2}$ de cristalizante $\mathrm{P}$ por demão para aplicação na argamassa, sendo necessárias duas demãos. A quantidade utilizada foi calculada de acordo com a área superficial da amostra que receberia o tratamento, sendo o traço indicado de 5 partes de pó para 2 partes de água.

As quantidades de cristalizantes aplicadas estão descritas na Tabela 6.

Previamente à aplicação do tratamento $\mathrm{R}$, o fornecedor recomenda a molhagem da superfície que recebe o cristalizante, saturando-a, mas sem a encharcar. Concluída essa etapa, aplicou-se diretamente o cristalizante $\mathrm{R}$ sobre as amostras com o auxílio de um pincel limpo, conforme a Figura 4.

Tabela 5 - Caracterização dos tratamentos cristalizantes

\begin{tabular}{c|c|c}
\hline Características & Tratamento R & Tratamento P \\
\hline Aparência & Líquido incolor & Sólido em pó, cor cinza \\
Densidade a $23^{\circ} \mathrm{C}\left(\mathrm{g} / \mathrm{cm}^{3}\right)$ & 1,20 & 1,45 \\
pH a $23^{\circ} \mathrm{C}$ & 11,0 & 12,5 \\
Viscosidade $\left(\right.$ Ford $\left.4-25^{\circ} \mathrm{C}\right)$ & $12 \mathrm{~s}$ & Não definido \\
\hline
\end{tabular}

Fonte: adaptada do fabricante dos aditivos.

Figura 3 - Simbologia gráfica com idade de ensaio e tratamento cristalizante utilizado

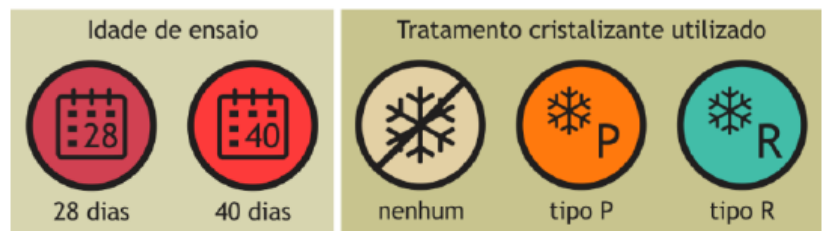

Tabela 6 - Quantidade dos cristalizantes R e P aplicados

\begin{tabular}{|c|c|c|c|c|c|}
\hline \multirow[b]{2}{*}{ Amostra } & \multirow[b]{2}{*}{ Quantidade } & \multirow[b]{2}{*}{$\begin{array}{c}\text { Área } \\
\text { unitária } \\
\left(\mathbf{m}^{2}\right)\end{array}$} & \multirow{2}{*}{$\begin{array}{c}\text { Cristalizante } \mathbf{R} \\
\text { Cristalizante } \\
\text { por superfície } \\
(\mathrm{ml})\end{array}$} & \multicolumn{2}{|c|}{ Cristalizante $\mathbf{P}$} \\
\hline & & & & $\begin{array}{l}\text { Cristalizante } \\
\text { - pó (g) }\end{array}$ & $\begin{array}{c}\text { Cristalizante } \\
\text { - água (g) }\end{array}$ \\
\hline $\begin{array}{c}\text { Placas circulares } \\
\mathrm{D}=10 \mathrm{~cm} \text { e altura } 2 \mathrm{~cm}\end{array}$ & 5 & 0,0176 & 4,4 & 10,05 & 4 \\
\hline $\begin{array}{c}\mathrm{CP} \\
7,5 \times 7,5 \times 5 \mathrm{~cm}^{*}\end{array}$ & 2 & 0,005625 & 1,4 & 3,2 & 1,3 \\
\hline $\begin{array}{c}\mathrm{CP} \\
4 \times 4 \times 16 \mathrm{~cm}\end{array}$ & 1 & 0,0016 & 0,4 & 0,9 & 0,4 \\
\hline $\begin{array}{l}\text { Placas retangulares } \\
50 \times 26 \times 2,5 \mathrm{~cm}\end{array}$ & 2 & 0,1313 & 32,8 & 75 & 30 \\
\hline
\end{tabular}

Nota: *os corpos de prova (CP) para o ensaio de abrasão receberam tratamento em ambos os lados, pois o ensaio exige a rotação das amostras após as primeiras 250 voltas.

Figura 4 - Aplicação do cristalizante $\mathbf{R}$ aos 28 dias

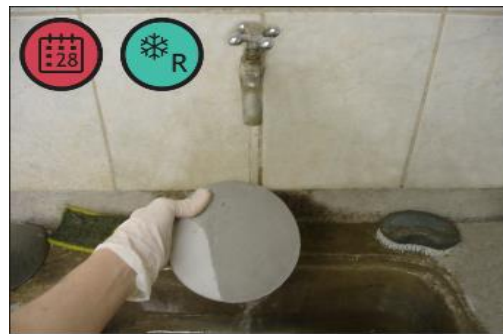

Molhagem prévia dos corpos de prova

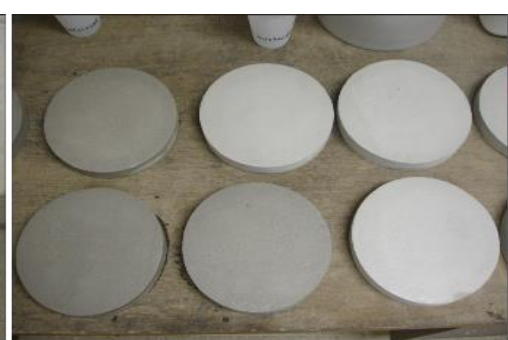

Corpos de prova saturados e $\operatorname{secos}$

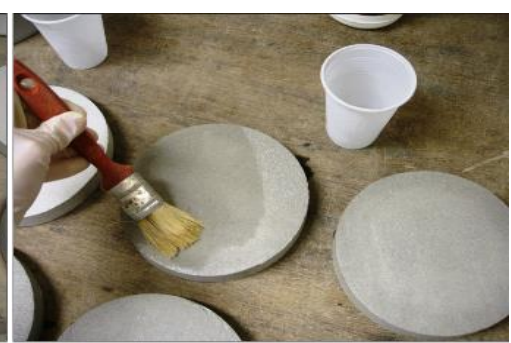

Aplicação do cristalizante tipo R 
Antes da aplicação do tratamento $\mathrm{P}$, o fornecedor recomenda a molhagem da superfície que recebe o cristalizante, saturando-a, mas sem a encharcar. O cristalizante e a água foram pesados de acordo com o definido para cada superfície de amostra, e ambos foram misturados. O fabricante recomenda ainda que o material seja usado em até $20 \mathrm{~min}$, o qual deve ser misturado constantemente. O cristalizante P foi aplicado diretamente sobre as amostras com o auxílio de pincel, conforme evidenciado na Figura 5.

\section{Técnicas de ensaio}

No Quadro 1 sintetizam-se as propriedades das argamassas avaliadas no estado fresco, para fins de caracterização do material, bem como as normas utilizadas para as determinações dessas propriedades.

Os ensaios de densidade de massa e de teor de ar incorporado foram executados segundo a NBR 13278 (ABNT, 2005a), com o emprego de um copo de aço inox com capacidade de $400 \mathrm{ml}$.

Por sua vez, no Quadro 2 apresentam-se as propriedades das argamassas avaliadas no estado endurecido, as normas utilizadas para a determinação e demais informações complementares aos ensaios. A moldagem dos corpos de prova seguiu as orientações da NBR 13279 (ABNT, 2005b).

A desmoldagem das amostras foi realizada aos 7 dias, uma vez que as $48 \mathrm{~h}$ recomendadas se revelaram insuficientes para esse tipo de argamassa devido à presença de aditivo retardador de pega na composição. A cura dos corpos de prova foi realizada ao ar, em ambiente de laboratório ( $20^{\circ} \mathrm{C}$ e $65 \%$ de umidade relativa), visto que a cura úmida não é comum em revestimentos de fachada. Os corpos de prova foram ensaiados em duas idades a fim de que pudesse ser feita a comparação entre as amostras antes e após a aplicação do tratamento cristalizante.

\section{Figura 5 - Aplicação do cristalizante $\mathrm{P}$ aos 28 dias}

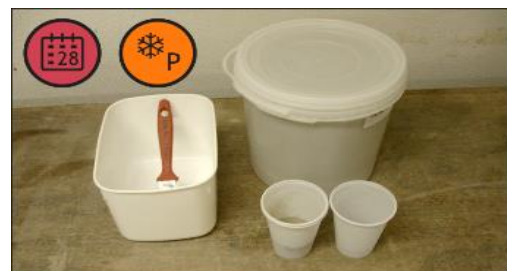

Preparação do material cristalizante



Aplicação do cristalizante P na amostra

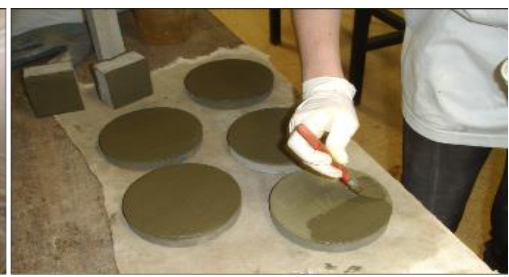

Aplicação da $2^{\text {a }}$ demão de cristalizante

Quadro 1 - Ensaios no estado fresco

\begin{tabular}{|c|c|}
\hline Ensaio no estado fresco & Norma de ensaio \\
\hline Densidade de massa e teor de ar incorporado & NBR 13278 (ABNT, 2005a) \\
\hline Exsudação de água & MR-6 (RÉUNION..., 1982) \\
\hline Índice de consistência & NBR 13276 (ABNT, 2016a) \\
\hline Retenção de água & NBR 13277 (ABNT, 2005c) \\
\hline
\end{tabular}

Quadro 2 - Ensaios no estado endurecido

\begin{tabular}{|c|c|c|c|c|}
\hline $\begin{array}{c}\text { Ensaio no estado } \\
\text { endurecido }\end{array}$ & $\begin{array}{c}\text { Número de amostras } \\
\text { e dimensões }\end{array}$ & $\begin{array}{c}\text { Norma de } \\
\text { ensaio }\end{array}$ & \multicolumn{2}{|c|}{ Idade de ensaio } \\
\cline { 4 - 5 } & $\begin{array}{c}68 \mathrm{CP} \\
\text { Resistência à } \\
\text { compressão }\end{array}$ & $\begin{array}{c}\text { NBR } 4 \times 16 \mathrm{~cm} \\
(\mathrm{ABNT}, 2005 \mathrm{~b})\end{array}$ & $3 \mathrm{CP}^{*}$ & $\mathbf{4 0}$ dias \\
\hline $\begin{array}{c}\text { Desgaste por } \\
\text { abrasão }\end{array}$ & $\begin{array}{c}6 \mathrm{CP} \\
7,5 \times 7,5 \times 5 \mathrm{~cm}\end{array}$ & $\begin{array}{c}\text { NBR 12042 } \\
(\mathrm{ABNT}, 2013)\end{array}$ & - & $6 \mathrm{CP}^{*}$ \\
\hline $\begin{array}{c}\text { Permeabilidade à } \\
\text { água }\end{array}$ & $\begin{array}{c}4 \text { placas retangulares } \\
50 \times 26 \times 2,5 \mathrm{~cm}\end{array}$ & - & $\begin{array}{c}4 \text { placas } \\
\text { retangulares }\end{array}$ & $\begin{array}{c}4 \text { placas } \\
\text { retangulares }\end{array}$ \\
\hline $\begin{array}{c}\text { Permeabilidade ao } \\
\text { vapor d'água }\end{array}$ & $\begin{array}{c}15 \text { placas circulares } \\
\mathrm{D}=10 \mathrm{~cm} \text { e altura } 2 \\
\mathrm{~cm}\end{array}$ & $\begin{array}{c}\text { EN 1015-19 } \\
(\text { COMITÉ.... } \\
2000)\end{array}$ & - & $\begin{array}{c}15 \text { placas } \\
\text { circulares }\end{array}$ \\
\hline
\end{tabular}

Nota: ${ }^{*} \mathrm{CP}=$ corpos de prova. 
A norma NBR 12042 (ABNT, 2013) estabelece as diretrizes para o ensaio de desgaste por abrasão e recomenda que sejam seguidas as diretrizes da NBR 12041 (ABNT, 2012) para o preparo dos corpos de prova de argamassa. Contudo, o abrasímetro utilizado não possuía sapata de acoplamento para corpos de prova cilíndricos, motivo pelo qual foram moldadas amostras de 7,5x7,5x5 cm, segundo as orientações de moldagem da NBR 13279 (ABNT, 2005b). Na realização do ensaio, dois corpos de prova foram acoplados em um abrasímetro do tipo Amsler da marca Contenco e sofreram desgaste através do anel giratório, cuja superfície recebe areia padrão IPT $\mathrm{n}^{\circ} 50$ para promover a abrasão do material. A medição das amostras foi realizada com o auxílio de um paquímetro.

Para a avaliação da permeabilidade à água, aplicou-se o método do cachimbo ou tubo Karsten. Portanto, foram confeccionadas 8 placas de $50 \times 26 \times 2,5 \mathrm{~cm}$ para investigar o comportamento apenas do material de revestimento, sem interferência do substrato ou das demais camadas. Dessas 8 placas, 4 foram utilizadas para a $\operatorname{argamassa}$ de $36 \mathrm{~h}$, e as outras 4 para a argamassa de $72 \mathrm{~h}$. Dessas 4 placas para cada tipo de argamassa, 2 receberam tratamento com o aditivo cristalizante P, e outras 2 com o cristalizante R. Foram empregados seis cachimbos do tipo piso/teto em cada placa, totalizando doze cachimbos para cada tipo de tratamento cristalizante, os quais foram vedados com silicone e, após, preenchidos com água até a marcação de $4 \mathrm{ml}$. Optou-se por esperar a coluna de água chegar ao fim, de forma a verificar mais detalhadamente o tempo necessário para a argamassa absorver todo o volume de água. Também se observou a área de molhagem na parte inferior da placa, a fim de verificar se o tratamento com aditivo cristalizante atuava tanto na superfície do material, quanto em profundidade. As placas sem tratamento superficial foram denominadas de " $\mathrm{A}_{1}$ ", " $\mathrm{A}_{2}$ ", " $\mathrm{B}_{1}$ " e " $\mathrm{B}_{2}$ " para as argamassas de $36 \mathrm{~h}$ e de " $\mathrm{C}_{1}$ ", " $\mathrm{C}_{2}$ ", " $\mathrm{D}_{1}$ " e " $\mathrm{D}_{2}$ " para as argamassas de $72 \mathrm{~h}$. Essas placas foram ensaiadas aos 28 dias. Finalizado o ensaio, foram aplicados os tratamentos cristalizantes nas mesmas placas, e, aos 40 dias, o experimento foi realizado novamente, conforme esquematizado na Figura 6.

O ensaio de permeabilidade ao vapor d'água para argamassas não é normatizado no Brasil, por isso se fez uso dos procedimentos descritos na norma EN 1015-19 (COMITÉ..., 2000). Os corpos de prova foram confeccionados com diâmetro de $10 \mathrm{~cm}$ e altura de $2 \mathrm{~cm}$, conforme o estudo de Temp (2014), e a cura foi ao ar. As amostras foram ensaiadas em câmara climatizada da marca Feutron, modelo KPK 200, à temperatura de $20 \pm 2{ }^{\circ} \mathrm{C}$ e umidade relativa de $95 \pm 5 \%$, e o copo de ensaio preenchido com solução saturada de nitrato de potássio $\left(\mathrm{KNO}_{3}\right)$. Foram moldadas 15 placas circulares para cada argamassa, e, aos 28 dias, 5 amostras receberam tratamento cristalizante do tipo $\mathrm{R}$ e 5 amostras do tipo $\mathrm{P}$, para, aos 40 dias, todas as amostras serem ensaiadas pelo método do copo, com pesagens diárias.

A resistência à compressão foi determinada conforme a NBR 13279 (ABNT, 2005b) aos 28 dias, sem aplicação de cristalizante, e posteriormente aos 40 dias, com aplicação dos tratamentos.

\section{Resultados e discussões}

\section{Ensaios no estado fresco}

A Tabela 7 apresenta os resultados obtidos para os ensaios realizados com as argamassas estabilizadas de 36 $\mathrm{h}$ e de $72 \mathrm{~h}$ no estado fresco, a fim de caracterizar as diferentes argamassas. Os resultados obtidos foram comparados aos de Casali et al. (2011), que avaliaram argamassas similares, enquadradas de acordo com a classificação estabelecida nas normas brasileiras.

Figura 6 - Esquema das condições do ensaio de permeabilidade à água das argamassas estabilizadas

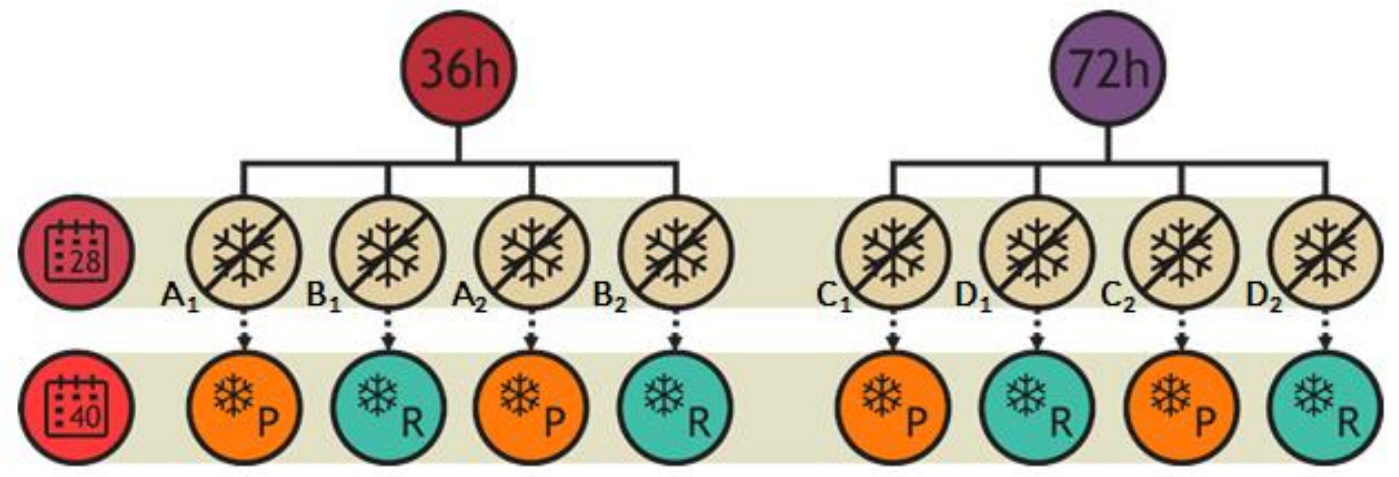


Tabela 7 - Resultados dos ensaios das argamassas estabilizadas no estado fresco

\begin{tabular}{|c|c|c|c|c|}
\hline \multirow{2}{*}{ Ensaio } & \multirow{2}{*}{ Fonte } & \multicolumn{3}{|c|}{ Tipo } \\
\hline & & & & $72 \mathrm{~h}$ \\
\hline \multirow{4}{*}{$\begin{array}{l}\text { Densidade de massa } \\
\qquad\left(\mathrm{kg} / \mathrm{m}^{3}\right)\end{array}$} & Pesquisa & 2.2 & $\begin{array}{l}\text { eal) } \\
\text { rica) }\end{array}$ & $\begin{array}{c}1.738 \text { (real) } \\
2.250 \text { (teórica) }\end{array}$ \\
\hline & \multirow[t]{2}{*}{ Casali et al. (2011) } & $\begin{array}{l}1.480 \\
\text { (real) }\end{array}$ & $\begin{array}{l}1.590 \\
(\mathrm{real})\end{array}$ & 1.600 (real) \\
\hline & & \multicolumn{2}{|c|}{2.170 (teórica) } & 2.170 (teórica) \\
\hline & NBR 13281 (ABNT, 2005d) & \multicolumn{2}{|c|}{ D4 (1.600-2.000) } & D4 (1.600-2.000) \\
\hline \multirow{2}{*}{$\begin{array}{c}\text { Teor de ar incorporado } \\
(\%)\end{array}$} & Pesquisa & \multicolumn{2}{|c|}{22} & 23 \\
\hline & Casali et al. (2011) & 31 & 27 & 26 \\
\hline Exsudação de água (\%) & Pesquisa & & & 0 \\
\hline \multirow{3}{*}{$\begin{array}{l}\text { Índice de consistência } \\
\qquad(\mathbf{m m})\end{array}$} & Pesquisa & \multicolumn{2}{|c|}{$223 \pm 0,37$} & $243 \pm 0,31$ \\
\hline & Casali et al. (2011) & 310 & 227 & 255 \\
\hline & NBR 16541 (ABNT, 2016b) & \multicolumn{2}{|c|}{$260 \pm 5$} & $260 \pm 5$ \\
\hline \multirow{3}{*}{$\begin{array}{c}\text { Retenção de água } \\
(\%)\end{array}$} & Pesquisa & \multicolumn{2}{|c|}{95} & 95 \\
\hline & Casali et al. (2011) & 30 & 50 & $>90$ \\
\hline & NBR 13281 (ABNT, 2005d) & \multicolumn{2}{|c|}{ U5 (91-97) } & U5 (91-97) \\
\hline
\end{tabular}

Ao se compararem os resultados obtidos na presente pesquisa com os de Casali et al. (2011), percebe-se que o elevado teor de ar incorporado é comum em se tratando de argamassas estabilizadas, enquanto para argamassas sem aditivos são obtidos teores mais baixos, na faixa entre $4 \%$ e $12 \%$ (BRUGALI; CASAGRANDE; STOLZ, 2019; SCHACKOW et al., 2019). Bellei e Caten (2019) também obtiveram teores na faixa entre $17 \%$ e $23 \%$ de ar incorporado para os lotes de argamassas estabilizadas analisados. Mesmo recebendo maior quantidade de aditivo incorporador de ar na composição, as argamassas de $72 \mathrm{~h}$, ao final do período de estabilização, atingem teores próximos às argamassas de $36 \mathrm{~h}$, devido ao colapso das bolhas de ar.

Conforme procedimento descrito no código MR-6 (REUNIÓN..., 1982), as amostras de argamassa estabilizada de $36 \mathrm{~h}$ e de $72 \mathrm{~h}$ não apresentaram exsudação de água, não evidenciando quantidade mensurável de água em sua superfície no decorrer das 4 h de realização do ensaio.

Os espalhamentos das argamassas de $36 \mathrm{~h}$ e de $72 \mathrm{~h}$ foram, em média, de $223 \mathrm{~mm}$ e de $243 \mathrm{~mm}$ respectivamente. Comparando-se as amostras ensaiadas, pode-se dizer que a argamassa de $72 \mathrm{~h}$ é mais trabalhável do que a argamassa de $36 \mathrm{~h}$, mesmo com os teores de ar incorporado muito próximos. Nakakura e Cincotto (2004) observaram que os aditivos presentes nas argamassas industrializadas modificam suas propriedades reológicas. Silva et al. (2005) também concluíram que a facilidade com que a argamassa é espalhada depende dos fenômenos de movimentação e de lubrificação existentes entre suas partículas internas, o que, nas argamassas industrializadas, é proporcionado pelo aditivo incorporador de ar. No entanto, maior quantidade de aditivo estabilizador de hidratação também pode contribuir para esse maior espalhamento devido à maior quantidade de água livre no sistema (ANTONIAZZI, 2019).

De acordo com a NBR 13281 (ABNT, 2005d), ambas as argamassas podem ser enquadradas na categoria U5 (91-97\% de retenção de água), ou seja, com alta retenção de água, e para a densidade de massa as duas argamassas podem ser enquadradas na categoria D4 $\left(1.600-2.000 \mathrm{~kg} / \mathrm{m}^{3}\right)$, segundo classificação da NBR 13281 (ABNT, 2005d).

\section{Ensaios no estado endurecido}

\section{Resistência à compressão}

Os resultados da presente pesquisa foram comparados aos parâmetros definidos pelas normas brasileira NBR 13281 (ABNT, 2005d) e europeia EN 998-1 (COMITÉ..., 2003), juntamente a resultados obtidos por outros pesquisadores. Quanto à norma europeia, as argamassas desta pesquisa foram classificadas como OC (one coat rendering mortar ou monocamada). Os resultados médios obtidos no estudo, seguidos do desvio padrão, são apresentados na Tabela 8. Para fins comparativos, também são apresentados resultados obtidos em estudos semelhantes. 
Tabela 8 - Resultados do ensaio de resistência à compressão das argamassas estabilizadas

\begin{tabular}{|c|c|c|c|c|c|c|}
\hline Fonte & \multicolumn{3}{|c|}{ Tipo } & $\begin{array}{l}\text { Resistência à } \\
\text { compressão } \\
\text { (MPa) }\end{array}$ & $\begin{array}{c}\text { NBR 13281 } \\
\text { (ABNT, 2005d) } \\
(\mathrm{MPa})\end{array}$ & $\begin{array}{c}\text { EN 998-1 } \\
(\text { COMITÉ..., 2003) } \\
\left(\mathrm{N} / \mathbf{m m}^{2}\right)\end{array}$ \\
\hline \multirow{8}{*}{ Pesquisa } & \multirow{4}{*}{$36 \mathrm{~h}$} & Sem & 28 dias & $13,79 \pm 1,30$ & \multirow{4}{*}{ P6 (>8) } & \multirow{4}{*}{$\operatorname{CS~IV~}(\geq 6)$} \\
\hline & & tratamento & 40 dias & $12,71 \pm 0,48$ & & \\
\hline & & \multicolumn{2}{|c|}{ Cristalizante $\mathrm{P}$} & $13,87 \pm 0,69$ & & \\
\hline & & \multicolumn{2}{|c|}{ Cristalizante $\mathrm{R}$} & $15,71 \pm 0,04$ & & \\
\hline & \multirow{4}{*}{$72 \mathrm{~h}$} & \multirow{2}{*}{$\begin{array}{c}\text { Sem } \\
\text { tratamento }\end{array}$} & 28 dias & $2,33 \pm 0,23$ & P2 $(1,5-3,0)$ & CS I $(0,4-2,5)$ \\
\hline & & & 40 dias & $4,13 \pm 0,39$ & P3 $(2,5-4,5)$ & CS III $(3,5-7,5)$ \\
\hline & & \multicolumn{2}{|c|}{ Cristalizante P } & $6,19 \pm 0,69$ & P4 $(4,0-6,5)$ & \multirow{2}{*}{$\operatorname{CS} \operatorname{IV}(\geq 6,0)$} \\
\hline & & Cristaliz & nte $\mathrm{R}$ & $6,65 \pm 0,69$ & P5 $(5,5-9,0)$ & \\
\hline \multirow{3}{*}{$\begin{array}{l}\text { Casali } \\
\text { et al. } \\
\text { (2011) }\end{array}$} & \multirow{2}{*}{$36 \mathrm{~h}$} & \multicolumn{2}{|c|}{$1^{\circ}$ dia sem película } & $\pm 5,0$ & P4 $(4,0-6,5)$ & CS III $(3,5-7,5)$ \\
\hline & & \multicolumn{2}{|c|}{$1^{\circ}$ dia sem película } & $\pm 9,0$ & P6 $(>8,0)$ & CS IV $(\geq 6,0)$ \\
\hline & $72 \mathrm{~h}$ & \multicolumn{2}{|c|}{$3^{\circ}$ dia com película } & $<2,0$ & $\mathrm{P} 1(\leq 2,0)$ & $\operatorname{CS~I}(0,4-2,5)$ \\
\hline
\end{tabular}

Comparando-se os resultados encontrados nesta pesquisa com os valores obtidos por Casali et al. (2011), pode-se observar um mesmo comportamento das argamassas, em que o traço de $36 \mathrm{~h}$ apresenta resistência superior ao traço de $72 \mathrm{~h}$, como mostra a Tabela 8. Essas diferenças também podem ser verificadas, de forma mais evidente, na Figura 7, que faz um comparativo entre as duas argamassas, em diferentes idades e com diferentes tratamentos.

A argamassa de $72 \mathrm{~h}$ recebeu maior quantidade de aditivo estabilizador de hidratação, o que acaba refletindo em uma diminuição de sua resistência mecânica (Figura 7), conforme também obtido por Bauer e Oliveira (2017) e Schackow et al. (2019). Isso acontece porque, a depender da quantidade de aditivo estabilizador de hidratação empregada, pode ocorrer, além do retardo no tempo de pega, atraso também no tempo para que sejam atingidas as propriedades mecânicas devido à formação mais tardia dos compostos hidratados (ANTONIAZZI, 2019). Pela Figura 7 é possível perceber isso: para a argamassa de 36 h, com menor teor de aditivo estabilizador de hidratação, a resistência praticamente não se alterou de 28 para 40 dias; já para a argamassa de $72 \mathrm{~h}$, houve aumento de $77 \%$ na resistência dentro nesse mesmo período. O uso dos cristalizantes aumentou a resistência aos 40 dias de ambas as argamassas, como se pode observar também na Figura 7, uma vez que esses aditivos atuam formando cristais no interior dos poros, o que pode aumentar a compacidade e a resistência delas.

\section{Desgaste por abrasão}

Os resultados da avaliação do desgaste por abrasão das argamassas e o desvio padrão obtido são apresentados na Figura 8.

Como se pode observar, no que diz respeito às argamassas de $36 \mathrm{~h}$, as amostras com aplicação do cristalizante $\mathrm{P}$ apresentaram menor desgaste. Isso pode ser atribuído, possivelmente, ao fato de que esse tipo de cristalizante cria uma nova camada cimentícia, mais resistente, sobre o corpo de prova. Na sequência, têm-se as amostras com o cristalizante R, o qual, segundo o fabricante, promove o endurecimento da superfície de aplicação, e, por fim, as argamassas sem tratamento, manifestando desgaste mais acentuado que as demais amostras, conforme esperado. O mesmo comportamento ocorreu nas argamassas de $72 \mathrm{~h}$, no entanto, por ser um material com menor resistência mecânica (Tabela 8), a diferença entre as amostras foi mais evidente. Dessa forma, percebeu-se maior eficácia dos cristalizantes para a argamassa de $72 \mathrm{~h}$, sendo capaz de reduzir o desgaste por abrasão em até 54\% com o cristalizante $\mathrm{P}$, reflexo do aumento proporcionado na resistência mecânica (Figura 8). Na Figura 9 ilustra-se o aspecto visual dos corpos de prova ao término do ensaio, demonstrando o maior desgaste relatado para a argamassa de $72 \mathrm{~h}$.

\section{Permeabilidade à água}

Os resultados médios obtidos para a permeabilidade à água, seguidos do desvio padrão, estão expressos na Tabela 9. Houve diferença nos coeficientes de absorção obtidos para as placas A e B, com a média das placas A apresentando menor absorção que as placas B, o que pode estar associado ao processo de moldagem e compactação. 
Figura 7 - Resistência à compressão das argamassas de $36 \mathrm{~h}$ e de $72 \mathrm{~h}$ sob diferentes tratamentos

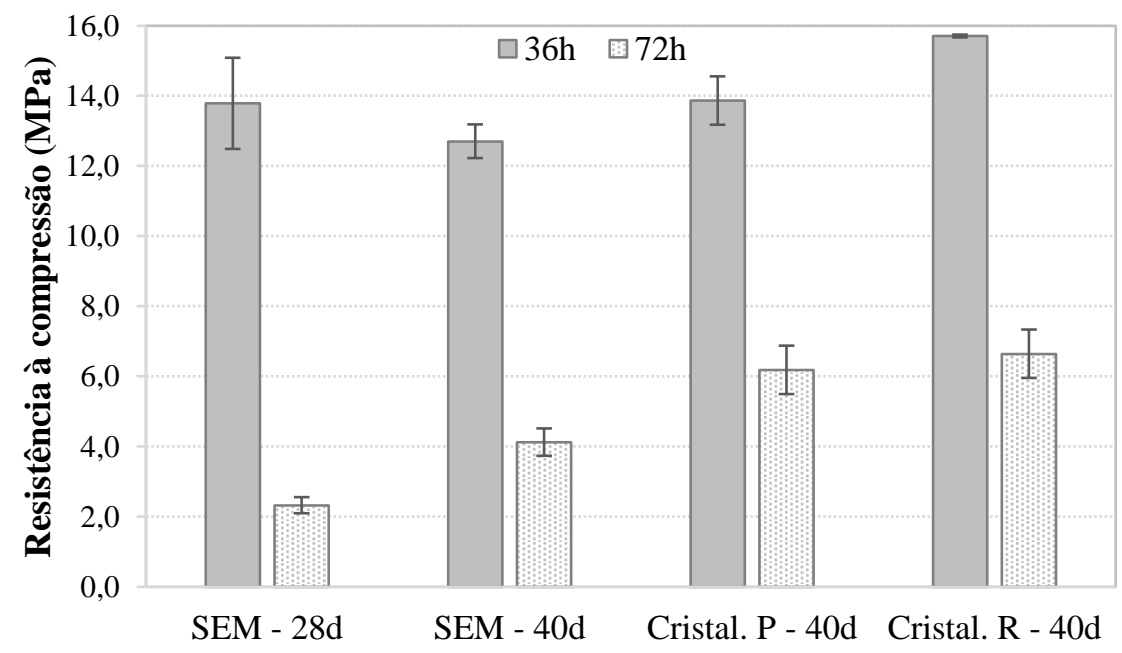

Figura 8 - Resultados do ensaio de desgaste por abrasão das argamassas estabilizadas aos 40 dias

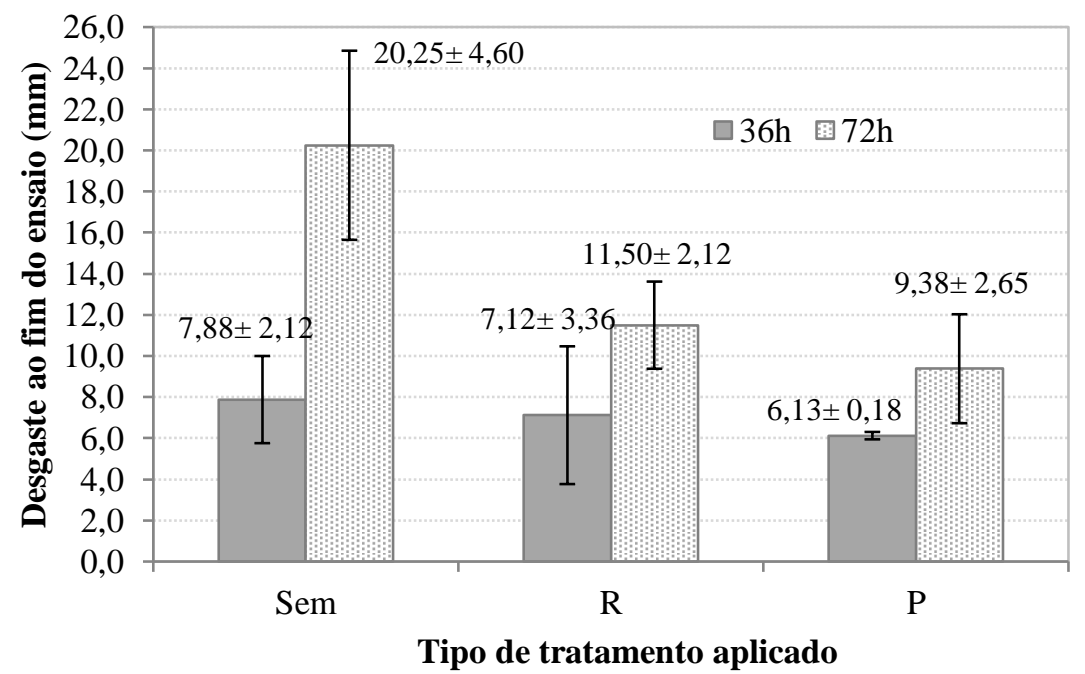

Figura 9 - Corpos de prova das argamassas estabilizadas após o término do ensaio de desgaste por abrasão

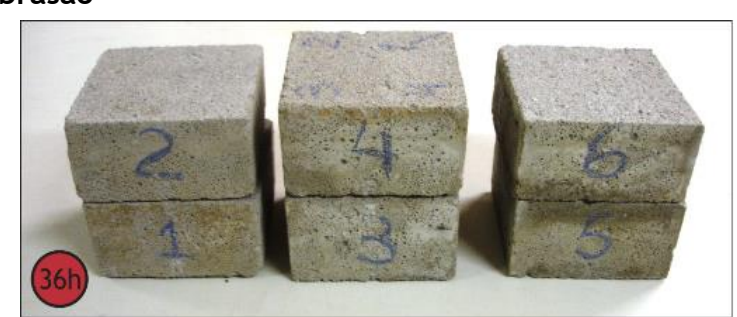

Corpos de prova de $36 \mathrm{~h}$ após o ensaio

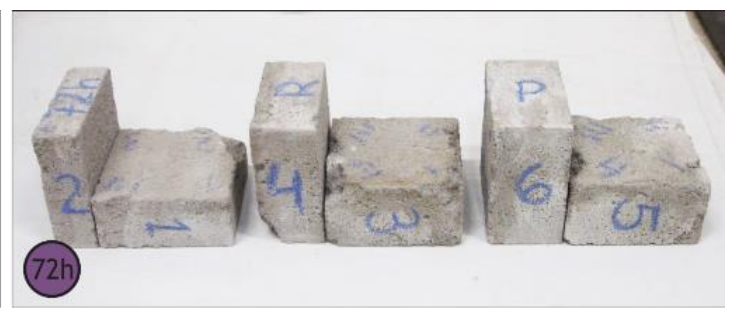

Corpos de prova de $72 \mathrm{~h}$ após o ensaio 
Tabela 9 - Resultados do ensaio de permeabilidade à água das argamassas estabilizadas

\begin{tabular}{|c|c|c|c|c|c|c|c|c|}
\hline \multirow{3}{*}{ Tratamento } & \multicolumn{4}{|c|}{$36 \mathrm{~h}$} & \multicolumn{4}{|c|}{$\overline{72 h}$} \\
\hline & \multicolumn{2}{|c|}{$\begin{array}{l}\text { Sem } \\
(28 d)\end{array}$} & \multicolumn{2}{|c|}{$\begin{array}{l}\text { Cristalizante } \\
\text { (40d) }\end{array}$} & \multicolumn{2}{|c|}{$\begin{array}{l}\text { Sem } \\
(28 d)\end{array}$} & \multicolumn{2}{|c|}{$\begin{array}{c}\text { Cristalizante } \\
\text { (40d) }\end{array}$} \\
\hline & $\begin{array}{c}\text { Placas } \\
\text { A }\end{array}$ & $\begin{array}{c}\text { Placas } \\
\text { B }\end{array}$ & $\begin{array}{c}\text { Placas } \\
\mathbf{P}\end{array}$ & $\begin{array}{c}\text { Placas } \\
\text { R }\end{array}$ & $\begin{array}{c}\text { Placas } \\
\text { C }\end{array}$ & $\begin{array}{c}\text { Placas } \\
\text { D }\end{array}$ & $\begin{array}{c}\text { Placas } \\
\mathbf{P}\end{array}$ & $\begin{array}{c}\text { Placas } \\
\mathbf{R}\end{array}$ \\
\hline $\begin{array}{l}\text { Duração do ensaio } \\
\text { (min) }\end{array}$ & 900 & 900 & 900 & 1500 & 180 & 180 & 720 & 360 \\
\hline $\begin{array}{l}\text { Coeficiente de } \\
\text { absorção } \\
\text { aos } 60 \text { min } \\
\left(\mathrm{kg} / \mathrm{m}^{2} \cdot \sqrt{h}\right)\end{array}$ & $\begin{array}{c}0,73 \\
\pm 0,05\end{array}$ & $\begin{array}{c}0,87 \\
\pm 0,11\end{array}$ & $\begin{array}{c}0,84 \\
\pm 0,14\end{array}$ & $\begin{array}{c}0,46 \\
\pm 0,08\end{array}$ & $\begin{array}{c}4,13 \\
\pm 0,21\end{array}$ & $\begin{array}{c}3,68 \\
\pm 0,33\end{array}$ & $\begin{array}{c}1,25 \\
\pm 0,43\end{array}$ & $\begin{array}{c}1,71 \\
\pm 0,40\end{array}$ \\
\hline CV (\%) & 12,2 & 21,1 & 26,8 & 30,0 & 8,4 & 14,5 & 55,8 & 38,3 \\
\hline
\end{tabular}

Nota: os resultados das placas $A, B, C$ e D da tabela correspondem à média entre as placas A1 e A2, B1 e B2, C1 e C2, e D1 e D2 respectivamente. Procedeu-se da mesma forma para as placas $\mathrm{P}$ e R.

Para as 4 placas de argamassa estabilizada de $36 \mathrm{~h}$ sem tratamento cristalizante (placas A e B), o ensaio completo durou 900 min (15 h). No entanto, aos 40 dias, após a aplicação do cristalizante R nas placas B, o tempo necessário para realização do ensaio aumentou para $1.500 \mathrm{~min}(25 \mathrm{~h})$, demonstrando o efeito benéfico do tratamento nas argamassas estabilizadas de $36 \mathrm{~h}$. Assim, houve redução de $47 \%$ no coeficiente de absorção de água da placa $\mathrm{R}$ em comparação à placa $\mathrm{B}$, evidenciada pelo gráfico da Figura 10 , o qual apresenta a média de absorção de água das placas de 36 h ao longo do tempo de ensaio. Já as placas A, de argamassa estabilizada de $36 \mathrm{~h}$, que receberam tratamento com o cristalizante do tipo $\mathrm{P}$ não demonstraram diferenças expressivas na absorção de água em relação às placas $\mathrm{B}$ com o cristalizante $\mathrm{R}$, conforme demonstra a Figura 10.

A Figura 11 mostra a absorção média de água ao longo do tempo de ensaio para as placas confeccionadas com a argamassas de 72 h, deixando evidente a ação dos cristalizantes sobre a absorção de água. Pode-se notar pelo gráfico da Figura 11 que as placas $\mathrm{C}$ apresentaram maior absorção de água em comparação às placas D, o que pode estar relacionado com o processo de moldagem e compactação.

As placas sem tratamento cristalizante (placas C e D) tiveram o ensaio completo em $180 \mathrm{~min}(3 \mathrm{~h})$, conforme exposto na Tabela 9. Contudo, aos 40 dias, após a aplicação do cristalizante $\mathrm{R}$ nas placas $\mathrm{D}$, o tempo necessário para a realização do ensaio aumentou para $360 \mathrm{~min}(6 \mathrm{~h})$, demonstrando que o cristalizante retardou a absorção da água nas argamassas estabilizadas de $72 \mathrm{~h}$, conforme mostra a Figura 11. Nas placas de argamassa estabilizada de $72 \mathrm{~h}$ que receberam tratamento com o cristalizante do tipo $\mathrm{P}$, o tempo necessário para a realização do ensaio aumentou para $720 \mathrm{~min}(12 \mathrm{~h})$. Assim, para a argamassa estabilizada de $72 \mathrm{~h}$, as placas $\mathrm{P}$ tiveram desempenho superior em relação às placas $\mathrm{R}$, reduzindo em $70 \%$ o coeficiente de absorção de água, ao contrário do que aconteceu com a argamassa estabilizada de $36 \mathrm{~h}$.

Fazendo um comparativo entre as absorções de água das placas confeccionadas com as argamassas de $36 \mathrm{~h}$ e de $72 \mathrm{~h}$, percebe-se que o aumento no teor dos aditivos ocasionou também maior permeabilidade à água, tanto para as placas sem tratamento, como para as placas com cristalizantes. Esse comportamento também foi obtido por Antoniazzi (2019), o qual associou o aumento da permeabilidade a menor resistência mecânica, a maior retração e às características dos poros proporcionadas por cada aditivo e teor empregados. Conforme explicado por Neville (2015), a permeabilidade de uma pasta de cimento varia com a evolução da hidratação. Como a argamassa de $72 \mathrm{~h}$ tem maior retardo no processo de hidratação devido à maior quantidade de aditivo estabilizador de hidratação empregada, já era esperado que ela apresentasse maior permeabilidade. Assim, a argamassa de 36 h, por já estar mais avançada no processo de hidratação e formação dos cristais, em uma mesma idade, tem menor permeabilidade, já que o volume total do gel preenche parte do espaço incialmente ocupado pela água. Após as primeiras idades, o tamanho, a forma e a concentração das partículas de gel, além da descontinuidade ou não dos capilares, é que definem a permeabilidade do material (NEVILLE, 2015).

A Figura 12 apresenta imagens obtidas após o ensaio de permeabilidade à água para as argamassas de $36 \mathrm{~h}$ (Figuras 12a e 12b) e para as argamassas de $72 \mathrm{~h}$ (Figuras 12c e 12d). 
Figura 10 - Absorção média de água da argamassa estabilizada de $36 \mathrm{~h}$ ao longo do tempo

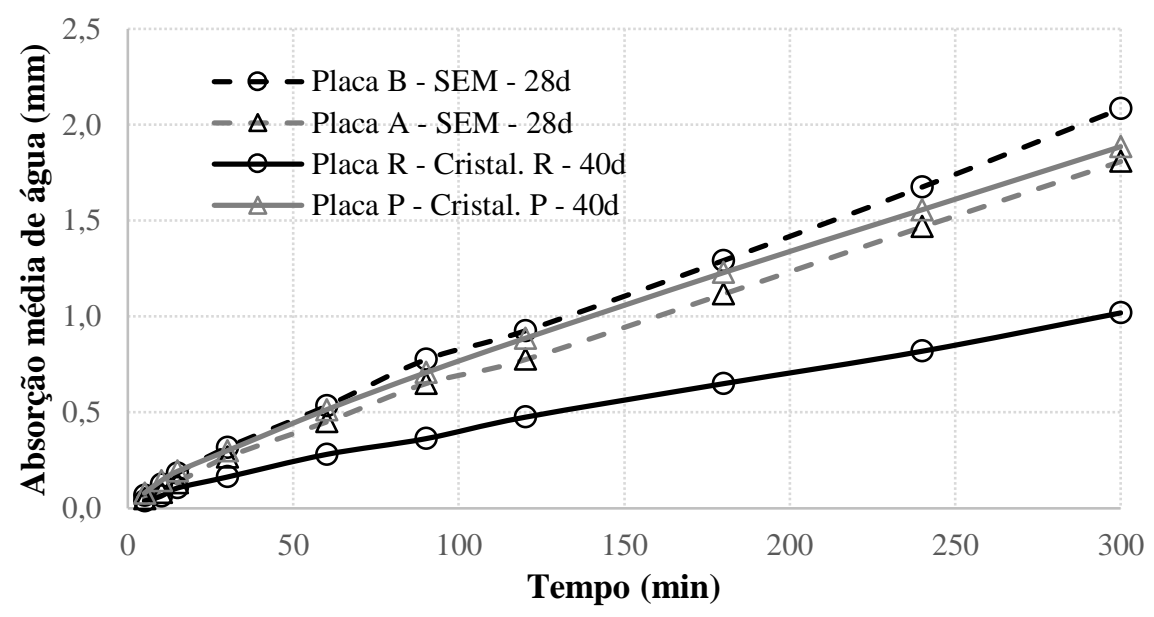

Figura 11 - Absorção média de água da argamassa estabilizada de $72 \mathrm{~h}$ ao longo do tempo

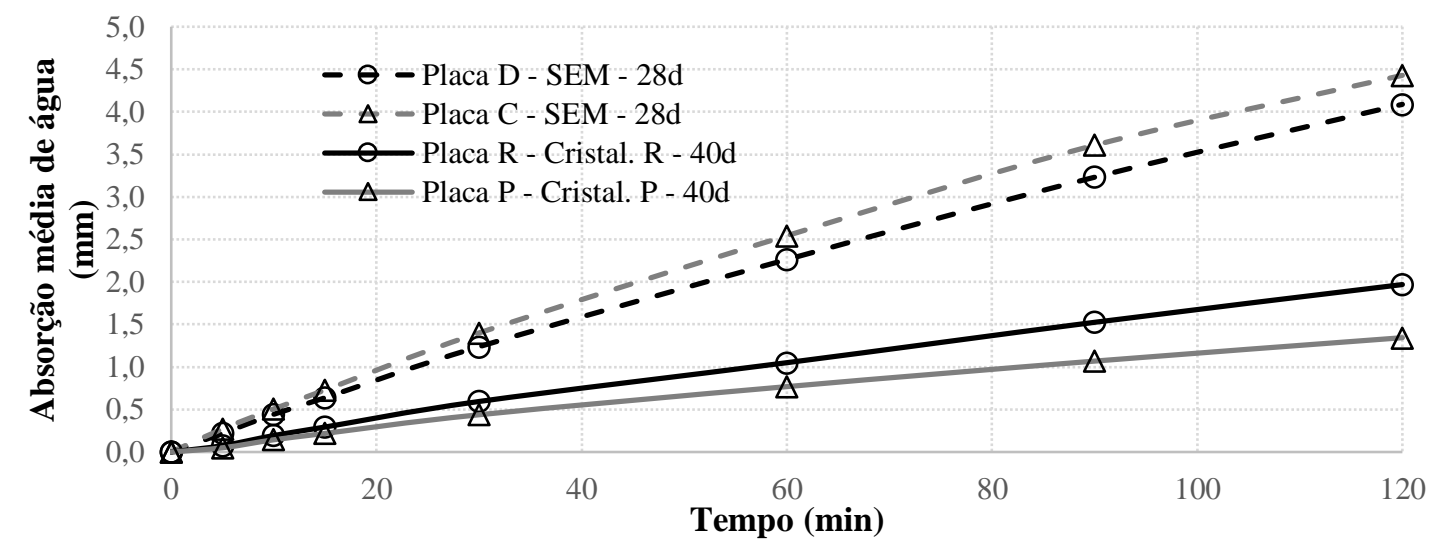

Figura 12 - Absorção de água no ensaio de permeabilidade das argamassas estabilizadas de $36 \mathrm{~h}$ e de $72 \mathrm{~h}$

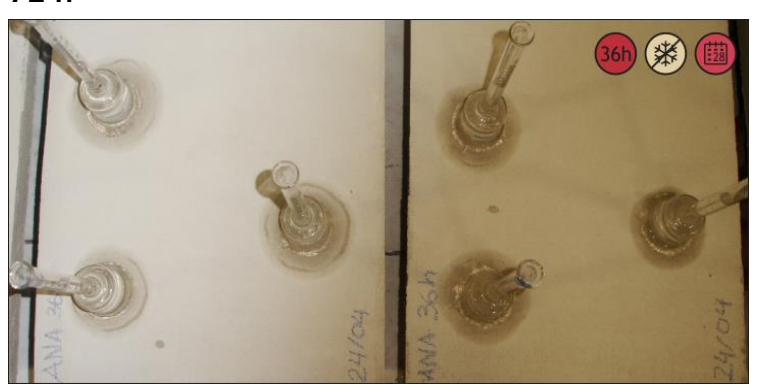

(a) Argamassas de $36 \mathrm{~h}$ sem cristalizante

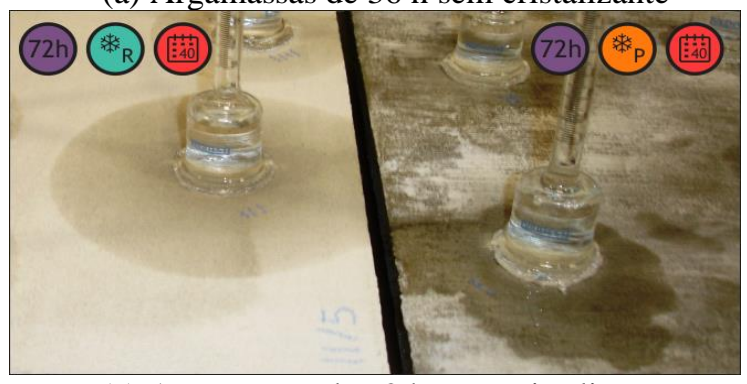

(c) Argamassas de $72 \mathrm{~h}$ com cristalizante

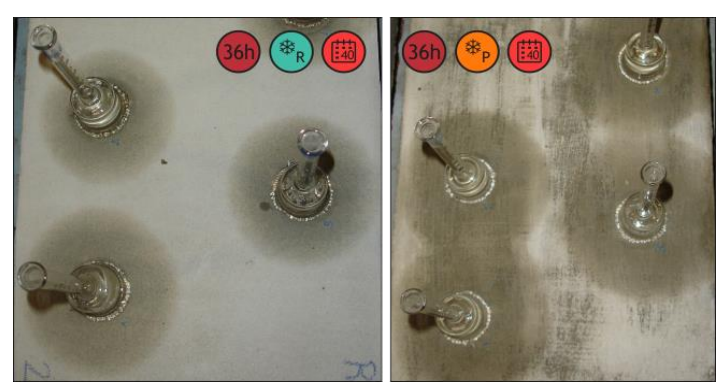

(b) Argamassas de $36 \mathrm{~h}$ com cristalizante

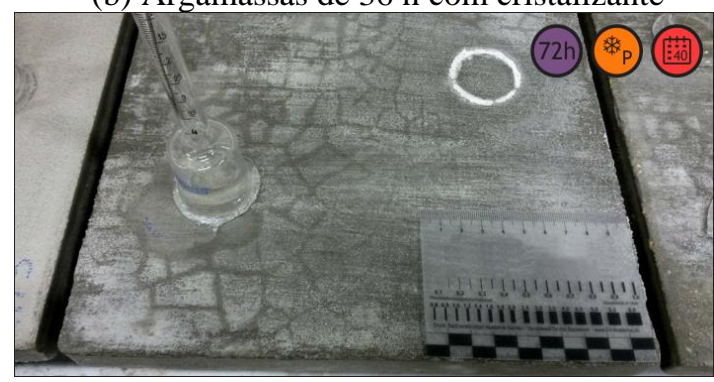

(d) Apresentando fissuras de retração, com aplicação do cristalizante $\mathrm{P}$, após o ensaio de permeabilidade à água 
As imagens do ensaio de permeabilidade à água das placas A e B (Figura 12a) mostram que as manchas por espalhamento de água não se estenderam pela placa, ficando concentradas em um diâmetro próximo à base do cachimbo. Esse fato pode indicar que a água estava penetrando verticalmente, mesmo que não se tenham percebido manchas na parte inferior da placa. Nos ensaios que ocorreram após a aplicação dos cristalizantes nas placas, foi possível perceber a alteração dessas características, com manchas de configuração radial, demonstrando um espalhamento de água de forma mais horizontal, conforme mostrado na Figura 12b. Isso pode ter ocorrido devido ao efeito dos cristalizantes que bloqueiam os poros e impedem a penetração de água em profundidade, fazendo com que ela percole mais facilmente pela superfície rasada.

A Figura 12c mostra através das manchas por espalhamento de água que as placas de argamassa estabilizada de $72 \mathrm{~h}$ com cristalizante R manifestaram absorção de água de forma simétrica, mediante a formação de uma circunferência cujo centro era o próprio cachimbo. Já nas placas com cristalizante $\mathrm{P}$, as manchas de água foram irregulares (Figura 12c), provavelmente devido à configuração das fissuras presentes na placa. Essas fissuras mapeadas na superfície da placa, como exemplificado na Figura 12d, se tornaram perceptíveis apenas após a absorção de água pela placa $\mathrm{P}$, o que pode ter ocorrido devido à retração diferencial entre a argamassa e o cristalizante.

\section{Permeabilidade ao vapor d'água}

Para as argamassas estabilizadas de 36 h ensaiadas, ao contrário do esperado, houve um acréscimo de massa no $2^{\circ}$ dia, fato esse que pode ter ocorrido porque a câmara ainda não havia conseguido estabilizar sua umidade relativa em $50 \%$, tendo permanecido em $85 \%$ durante esse dia. A partir do $5^{\circ}$ dia, em que aconteceu a estabilização da umidade relativa, a perda de massa das amostras foi contínua. A evolução da perda de massa diária das amostras é apresentada na Figura 13.

Já no caso das argamassas estabilizadas de 72 h, a perda de massa se mostrou contínua do primeiro ao último dia de ensaio, conforme a Figura 14.

Tanto nos ensaios das argamassas de $36 \mathrm{~h}$, quanto nos das de $72 \mathrm{~h}$, a perda de massa foi mais expressiva nas amostras com cristalizante $\mathrm{R}$, enquanto as com cristalizante $\mathrm{P}$ se mostraram menos permeáveis ao fluxo de vapor.

Quanto à permeância $(\Lambda)$ e a permeabilidade $(\pi)$ das amostras, tanto a argamassa de $36 \mathrm{~h}$ quanto a de $72 \mathrm{~h}$ obtiveram resultados similares em relação à aplicação de tratamento cristalizante. Na Tabela 10 são apresentados os resultados médios para cada tratamento superficial e para as argamassas sem tratamento.

Figura 13 - Resultados de perda de massa diária da argamassa estabilizada de $36 \mathrm{~h}$

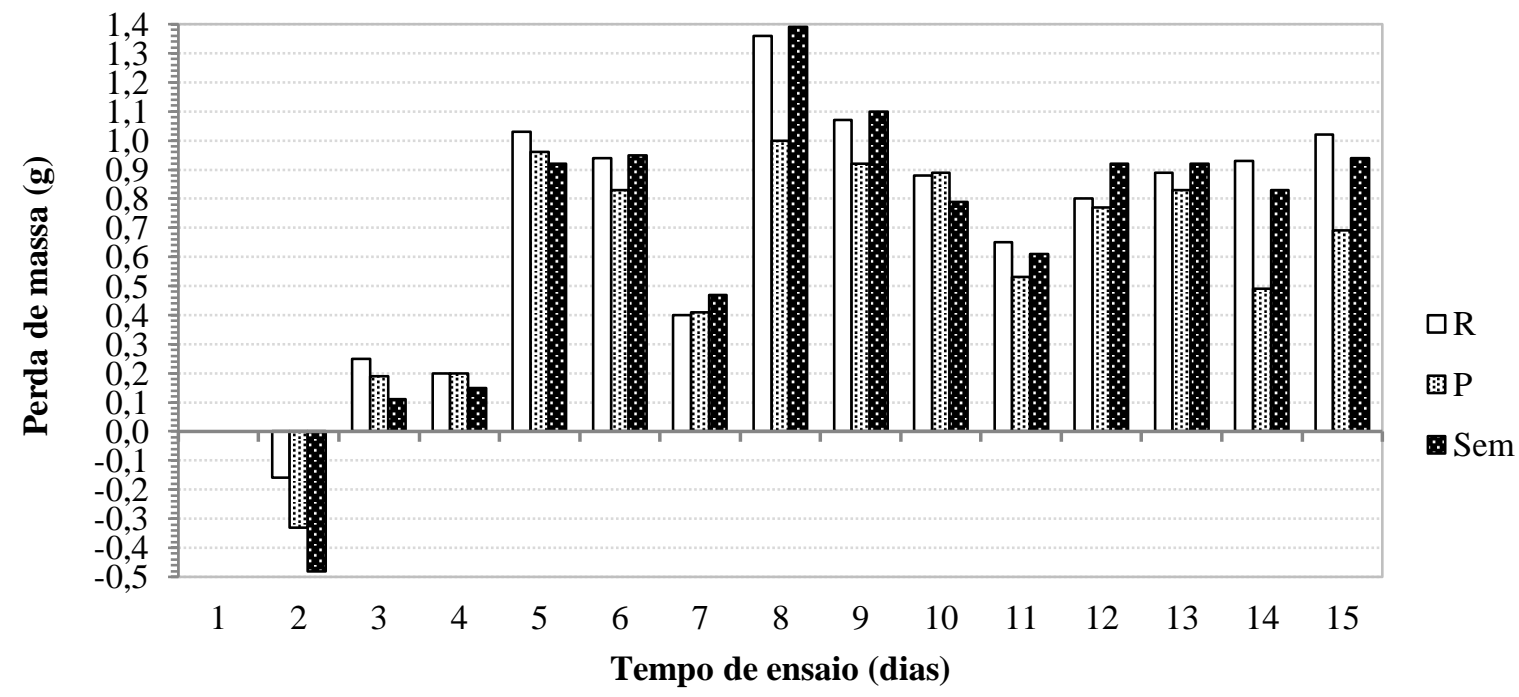


Figura 14 - Resultados de perda de massa diária da argamassa estabilizada de $72 \mathrm{~h}$



Tabela 10 - Resultados do ensaio de permeabilidade ao vapor das argamassas estabilizadas

\begin{tabular}{c|c|c|c|c|c|c}
\hline Tipo & \multicolumn{3}{|c|}{$\mathbf{3 6 ~ h}$} & \multicolumn{3}{c}{$\mathbf{7 2 ~ \mathbf { ~ }}$} \\
\hline Tratamento & Sem & $\mathbf{P}$ & $\mathbf{R}$ & $\mathbf{S e m}$ & $\mathbf{P}$ & $\mathbf{R}$ \\
\hline $\begin{array}{c}\text { Perda de massa } \\
(\mathrm{g})\end{array}$ & 9,69 & 8,39 & 10,23 & 8,27 & 6,94 & 9,84 \\
\hline $\begin{array}{c}\text { Permeância } \Lambda \\
\left(\mathrm{kg} / \mathrm{m}^{2} . \mathrm{s.Pa}\right)\end{array}$ & $9,89 \mathrm{E}^{-10}$ & $8,50 \mathrm{E}^{-10}$ & $10,47 \mathrm{E}^{-10}$ & $8,37 \mathrm{E}^{-10}$ & $6,98 \mathrm{E}^{-10}$ & $10,05 \mathrm{E}^{-10}$ \\
\hline $\begin{array}{c}\text { Permeabilidade } \Pi \\
(\mathrm{ng} / \mathrm{m} . \mathrm{s.Pa})\end{array}$ & 19,78 & 17,01 & 20,95 & 16,75 & 13,96 & 20,09 \\
\hline $\begin{array}{c}\text { Coeficiente de } \\
\text { permeabilidade } \mu \\
\begin{array}{c}\text { EN 998-1 } \\
(\mathrm{CEN}, 2003)\end{array}\end{array}$ & $0,20 \pm 0,02$ & $0,23 \pm 0,03$ & $0,19 \pm 0,03$ & $0,23 \pm 0,02$ & $0,28 \pm 0,02$ & $0,19 \pm 0,01$ \\
\hline
\end{tabular}

Comparando-se as argamassas, verificou-se que a de $36 \mathrm{~h}$ apresentou maior permeabilidade ao vapor d'água do que a de 72 h, o que pode estar associado à configuração, ao tamanho e à distribuição dos poros. Diferentemente da permeabilidade à água, a permeabilidade ao vapor é uma propriedade desejável para as argamassas, a fim de que possam expelir a umidade interna, realizando a transpiração do revestimento.

Todas as amostras que receberam tratamento com o cristalizante $\mathrm{P}$ tiveram transmissão de vapor reduzida. Isso se deve ao fato de que esse cristalizante cria uma nova camada cimentícia sobre a amostra, a qual penetra nos poros, vedando-os e também dificultando a passagem do vapor. Em contraponto, as amostras com o cristalizante $\mathrm{R}$ se mostraram mais permeáveis ao vapor do que as que não receberam tratamento. Esse efeito é descrito pelo fabricante do cristalizante $\mathrm{R}$, que promete a livre passagem de água em forma de vapor, mas não em forma líquida. Ainda se constatou que a argamassa de $36 \mathrm{~h}$ é mais permeável que a de $72 \mathrm{~h}$, indicando, possivelmente, maior conexão entre os poros internos.

\section{Conclusões}

De acordo com os estudos desenvolvidos, pode-se concluir que:

(a) a argamassa de $36 \mathrm{~h}$ apresentou maior resistência mecânica, menor permeabilidade à água e maior permeabilidade ao vapor do que a argamassa de $72 \mathrm{~h}$, demonstrando ser mais apropriada para aplicação;

(b) o maior teor de aditivos empregado na argamassa de $72 \mathrm{~h}$ a fim de proporcionar aumento no tempo de pega e, assim, trabalhabilidade, possivelmente ocasionou atraso no processo de hidratação, o que também refletiu em menor resistência, mesmo em idade maior, e maior permeabilidade à água; 
(c) a aplicação dos tratamentos cristalizantes foi eficiente para melhorar a estanqueidade de ambas as argamassas, assim como também contribuiu para o aumento da resistência, especialmente para a argamassa de $72 \mathrm{~h}$;

(d) o cristalizante $\mathrm{P}$ proporcionou redução de $70 \%$ no coeficiente de absorção de água da argamassa de 72 $\mathrm{h}$, não demonstrando eficiência para as argamassas de $36 \mathrm{~h}$. Além disso, por formar uma barreira física sobre a superfície da argamassa, também reduziu o fluxo de vapor, o que é prejudicial aos revestimentos;

(e) o cristalizante $\mathrm{R}$ reduziu a absorção de água em aproximadamente a metade para ambas as argamassas, não comprometendo a permeabilidade ao vapor, o que o tornaria mais indicado para a aplicação em argamassas estabilizadas;

(f) o estudo mostrou o quanto a utilização de aditivos cristalizantes pode contribuir com a resistência mecânica e a permeabilidade das argamassas estabilizadas, no entanto estudos prévios se mostram necessários para a avaliação da viabilidade de aplicação em cada caso, levando em consideração não somente os efeitos sobre a permeabilidade à água líquida, mas também ao vapor; e, por fim,

(g) reforça-se a necessidade de normativas específicas para embasarem a produção e a aplicação de argamassas estabilizadas, visto que a comercialização desses produtos é baseada no tempo de trabalhabilidade, o qual está vinculado diretamente à dosagem dos aditivos, que, por sua vez, pode comprometer o desempenho dos revestimentos.

\section{Referências}

AL-KHEETAN, M. J.; RAHMAN, M. M.; CHAMBERLAIN, D. A. Development of hydrophobic concrete by adding dual-crystalline admixture at mixing stage. Structural Concrete, v. 19, n. 5, p. 1504-1511, 2018 b.

AL-KHEETAN, M. J.; RAHMAN, M. M.; CHAMBERLAIN, D. A. Remediation and protection of masonry structures with crystallising moisture blocking treatment. International Journal of Building Pathology and Adaptation, v. 36, n. 1, p. 77-92, 2018a.

ALVES, N. J. D.; DO Ó, S. W. Aditivos incorporadores de ar e retentores de água. In: BAUER, E. (ed.). Revestimentos de argamassa: características e peculiaridades. Brasília: Sinduscon-DF; LEM-UnB, 2005.

ANTONIAZZI, J. P. O efeito dos aditivos incorporador de ar e estabilizador de hidratação nas propriedades das argamassas estabilizadas. Santa Maria, 2019. 258 p. Tese (Doutorado em Engenharia Civil) - Programa de Pós-Graduação em Engenharia Civil, Universidade Federal de Santa Maria, Santa Maria, 2019.

ASSOCIAÇÃO BRASILEIRA DE NORMAS TÉCNICAS. NBR 12042: materiais inorgânicos: determinação do desgaste por abrasão. Rio de Janeiro, 2013.

ASSOCIAÇÃO BRASILEIRA DE NORMAS TÉCNICAS. NBR 12041: argamassa de alta resistência para pisos: determinação da resistência à compressão simples e tração por compressão diametral. Rio de Janeiro, 2012.

ASSOCIAÇÃO BRASILEIRA DE NORMAS TÉCNICAS. NBR 13276: argamassa para assentamento e revestimento de paredes e tetos: preparo da mistura e determinação do índice de consistência. Rio de Janeiro, $2016 \mathrm{a}$.

ASSOCIAÇÃO BRASILEIRA DE NORMAS TÉCNICAS. NBR 13277: argamassa para assentamento e revestimento de paredes e tetos: determinação da retenção de água. Rio de Janeiro, 2005c.

ASSOCIAÇÃO BRASILEIRA DE NORMAS TÉCNICAS. NBR 13278: argamassa para assentamento e revestimento de paredes e tetos: determinação da densidade de massa e teor de ar incorporado. Rio de Janeiro, 2005a.

ASSOCIAÇÃO BRASILEIRA DE NORMAS TÉCNICAS. NBR 13279: argamassa para assentamento e revestimento de paredes e tetos: determinação da resistência à tração na flexão e à compressão. Rio de Janeiro, 2005b.

ASSOCIAÇÃO BRASILEIRA DE NORMAS TÉCNICAS. NBR 13281: argamassa para assentamento e revestimento de paredes e tetos: requisitos. Rio de Janeiro, 2005d. 
ASSOCIAÇÃO BRASILEIRA DE NORMAS TÉCNICAS. NBR 16541: argamassa para assentamento e revestimento de paredes e tetos: preparo da mistura para a realização de ensaios. Rio de Janeiro, 2016b.

ASSOCIAÇÃO BRASILEIRA DE NORMAS TÉCNICAS. NBR 16697: cimento Portland: requisitos. Rio de Janeiro, 2018.

ASSOCIAÇÃO BRASILEIRA DE NORMAS TÉCNICAS. NBR 7211: agregados para concreto: especificação. Rio de Janeiro, 2019.

BAUER, E. et al. Requisitos das argamassas estabilizadas para revestimento. In: SIMPÓSIO BRASILEIRO DE TECNOLOGIA DAS ARGAMASSAS, 11., Porto Alegre. Anais [...] Porto Alegre, 2015.

BAUER, E.; OLIVEIRA, V. C. Comportamentos e propriedades das argamassas estabilizadas de revestimentos. In: SIMPÓSIO BRASILEIRO DE TECNOLOGIA DAS ARGAMASSAS, 12., São Paulo, 2017. Anais [...] São Paulo, 2017.

BELLEI, P.; CATEN, A. T. Avaliação do desempenho da argamassa estabilizada de $36 \mathrm{e} 72 \mathrm{~h}$ para revestimento externo em diferentes tempos de utilização e modo de armazenamento. In: SIMPÓSIO BRASILEIRO DE TECNOLOGIA DAS ARGAMASSAS, 13., Goiânia, 2019. Anais [...] Goiânia, 2019.

BRUGALI, D. R.; CASAGRANDE, E.; STOLZ, C. M. Caracterização de argamassas industrializadas e estabilizadas disponíveis em Caxias do Sul/RS. In: SIMPÓSIO BRASILEIRO DE TECNOLOGIA DAS ARGAMASSAS, 13., Goiânia, 2019. Anais [...] Goiânia, 2019.

CAMPOS, G. M.; MACIOSKI, G.; CASALI, J. M. Estudo do tempo de início de pega de argamassas com aditivo estabilizador de hidratação. In: CONGRESSO BRASILEIRO DO CONCRETO, 55., Gramado, 2013. Anais [...] Gramado, 2013

CASALI, J. M. et al. Avaliação das propriedades do estado fresco e endurecido da argamassa estabilizada para assentamento e revestimento. In: SIMPÓSIO BRASILEIRO DE TECNOLOGIA DAS ARGAMASSAS, 9., Minas Gerais, 2011. Anais [...] Minas Gerais, 2011.

CASALI, J. M. et al. Influence of cement type and water content on the fresh state properties of ready mix mortar. Ambiente Construído, Porto Alegre, v. 18, n. 2, p. 33-52, abr./jun. 2018.

CHEUNG, J. et al. Impact of admixtures on the hydration kinetics of portland cement. Cement and Concrete Research, v. 41, n. 12, p. 1289-1309, 2011.

COMITÉ EUROPÉEN DE NORMALISATION. EN 1015-19: methods of test for mortar for masonry: part 19: determination of water vapor permeability of hardened rendering and plastering mortars. Brussels, 2000.

COMITÉ EUROPÉEN DE NORMALISATION. EN 998-1: specification for mortar for masonry: part 1: rendering and plastering mortar. Brussels, 2003.

FUKUI, E. et al. Efeito do procedimento de mistura no comportamento no estado fresco de argamassas de revestimento produzida em obra e industrializada. Revista Matéria, Rio de Janeiro, v. 23, n. 1, p. e-11956, 2018.

GRANNEMAN, S. J. C.; LUBELLI, B.; VAN HEES, R. P. J. Effect of mixed in crystallization modifiers on the resistance of lime mortar against $\mathrm{NaCl}$ and $\mathrm{Na}_{2} \mathrm{SO}_{4}$ crystallization. Construction and Building Materials, v. 194, p. 62-70, 2019.

GUINDANI, E. N. Argamassa estabilizada para revestimento: avaliação da influência da adição de finos nas propriedades do estado fresco e endurecido. Florianópolis, 2018. Dissertação (Mestrado em Engenharia Civil) - Programa de Pós-Graduação em Engenharia Civil, Universidade Federal de Santa Catarina, Florianópolis, 2018.

HODUL, J. et al. Influence of crystallization admixture on mechanical parameters and microstructure of polymer-cement mortars with waste limestone. Solid State Phenomena, v. 296, p. 27-34, 2019.

KEBHARD, J. M.; KAZMIERCZAK, C. S. Avaliação do comportamento de uma argamassa estabilizada ao longo de seu tempo de estabilização. In: SIMPÓSIO BRASILEIRO DE TECNOLOGIA DAS ARGAMASSAS, 12., São Paulo, 2017. Anais [...] São Paulo, 2017.

LOOTENS, D.; BENTZ, D. P. On the relation of setting and early-age strength development to porosity and hydration in cement- based materials. Cement and Concrete Composites, v. 68, p. 9-14, 2016. 
MATOS, P. R. Estudo da utilização de argamassa estabilizada em alvenaria estrutural de blocos de concreto. Florianópolis, 2013. 74 f. Monografia (Graduação em Engenharia Civil) - Universidade Federal de Santa Catarina, Florianópolis, 2013.

NAKAKURA, E. H.; CINCOTTO, M. A. Análise dos requisitos de classificação de argamassas de assentamento e revestimento. São Paulo: Epusp, 2004. Boletim Técnico da USP.

NEVILLE, A. M. Propriedades do concreto. 5. ed. Porto Alegre: Bookman, 2015.

NEVILLE, A. M.; BROOKS, J. J. Tecnologia do concreto. 2. ed. Porto Alegre: Bookman, 2013.

OLIVEIRA, V. C. Estudo comportamental da formulação, dos requisitos e das propriedades das argamassas estabilizadas de revestimento. Brasília, 2017. Dissertação (Mestrado em Estruturas e Construção Civil) - Universidade de Brasília, Brasília, 2017.

PAOLINI, M.; KHURANA, R. Admixtures for recycling of waste concrete. Cement and Concrete Composites, v. 20, p. 221-229, 1998.

REITERMAN, P.; BÄUMELT, V. Long-term sorption properties of mortars modified by crystallizing admixture. Advanced Materials Research, v. 1054, p. 71-74, 2014.

RÉUNION INTERNATIONALE DES LABORATOIRES ET EXPERTS DES MATÉRIAUX. MR-6: tendency of water to separate from mortars bleeding. France, 1982.

ROMANO, R. C. O. et al. Impacto do tipo de misturador e do tempo de mistura nas propriedades de argamassas industrializadas. Ambiente Construído, Porto Alegre, v. 9, n. 4, p. 109-118, out./dez, 2009.

ROMANO, R. C. O. et al. Impacto do uso de incorporador de ar nas propriedades reológicas de argamassas. In: SIMPÓSIO BRASILEIRO DE TECNOLOGIA DAS ARGAMASSAS, 9., Belo Horizonte, 2011. Anais [...] Belo Horizonte, 2011.

ROMANO, R. C. O.; CINCOTTO, M. A.; PILEGGI, R. G. Incorporação de ar em materiais cimentícios: uma nova abordagem para o desenvolvimento de argamassas de revestimento. Ambiente Construído, Porto Alegre, v. 18, n. 2, p. 289-308, abr./jun. 2018.

SCHACKOW, A. et al. Stabilized mortar with air incorporator agent and plasticizer set retarder: performance measurement. Revista IBRACON de Estruturas e Materiais, São Paulo, v. 12, n. 6, p. 12481259, dez. 2019.

SILVA, R. et al. Avaliação do comportamento da argamassa no estado fresco através dos métodos de mesa de consistência, dropping ball e squeeze flow. In: SIMPÓSIO BRASILEIRO DE TECNOLOGIA DAS ARGAMASSAS, 6., Florianópolis, 2005. Anais [...] Florianópolis, 2005.

TEMP, A. L. Avaliação de revestimentos de argamassa à permeabilidade ao vapor de água. Santa Maria, 2014. Dissertação (Mestrado em Engenharia Civil) - Universidade Federal de Santa Maria, Santa Maria, 2014.

WATTS, B. E.; FERRARO C. Prediction of setting for admixture modified mortars using the VCCTL. Cement and Concrete Composites, v. 78, p. 63-72, 2017. 


\section{Ana Cláudia Akele Jantsch}

Programa de Pós-Graduação em Engenharia Civil | Universidade Federal de Santa Maria | Av. Roraima, 1000, Prédio Inpe, Sala 2061, Cidade Universitária | Santa Maria - RS - Brasil | CEP 97105-900 | Tel.: (51) 99289-6373 | E-mail: akele.jantsch@gmail.com

Gihad Mohamad

Departamento de Estruturas e Construção Civil | Universidade Federal de Santa Maria | Tel.: (55) 98142-2533 | E-mail: gihad@ufsm.br

Raquel Petry Brondani Schmidt

Departamento de Expressão Gráfica | Universidade Federal de Santa Maria | Tel.: (55) 99944-7287 | E-mail: raquelbrondani@gmail.com

Juliana Pippi Antoniazzi

Departamento de Expressão Gráfica | Universidade Federal de Santa Maria | Tel.: (55) 99965-9089 | E-mail: juliana.antoniazzi@ufsm.br

\section{André Lübeck}

Departamento de Estruturas e Construção Civil | Universidade Federal de Santa Maria | Tel.: (55) 99961-5173 | E-mail: andrelubeck@gmail.com

\section{Ambiente Construído}

Revista da Associação Nacional de Tecnologia do Ambiente Construído

Av. Osvaldo Aranha, $99-3^{\circ}$ andar, Centro

Porto Alegre - RS - Brasil

CEP $90035-190$

Telefone: +55 (51) 3308-4084

Fax: +55 (51) 3308-4054

www.seer.ufrgs.br/ambienteconstruido

E-mail: ambienteconstruido@ufrgs.br

This is an open-access article distributed under the terms of the Creative Commons Attribution License. 